\title{
Rapid hull collapse strength calculations of double hull oil tankers after collisions
}

\author{
Muhammad Faisal ${ }^{1,2}$, Sung Hwan Noh ${ }^{1,2}$, Md. Rokan Uddin Kawsar ${ }^{1,2}$, Samy A.M. Youssef ${ }^{3}$, Jung Kwan Seo ${ }^{1,}$ \\ 2 , Yeon Chul $\mathrm{Ha}^{1,2}$ and Jeom Kee Paik ${ }^{1,2,4^{*}}$ \\ ${ }^{1}$ Department of Naval Architecture and Ocean Engineering, Pusan National University, Busan, Korea \\ ${ }^{2}$ The Korea Ship and Offshore Research Institute (The Lloyd's Register Foundation Research Centre of Excellence), \\ Pusan National University, Busan, Korea \\ ${ }^{3}$ Marine Engineering Technology Department, Arab Academy for Science, Technology and Maritime Transport, \\ Alexandria, Egypt \\ ${ }^{4}$ Department of Mechanical Engineering, University College London, London, UK \\ * Corresponding author: J.K. Paik, (Tel) +82 51510 2429, (Fax) +82 51518 7687, jeompaik@ pusan.ac.kr
}

\begin{abstract}
The primary objective of the present study is to develop a rapid method for calculating hull collapse strength of double hull oil tankers after collisions. For this purpose, the statistical characteristics of hull girder collapse after collision are studied. Four double hull oil tankers with different size are considered: Panamax, Aframax, Suezmax and VLCC. A set of 50 credible collision scenarios are selected by a sampling technique associated with the collision hazard identification based on the historical ship collision database. Four parameters, namely vertical collision location, damage penetration, striking ship's bulbous bow height, and striking ship's bulbous bow length are determined as a consequence of the corresponding collision scenario. The intelligent supersize finite element method is used to compute the progressive collapse behaviour of hull girder structures with the collision damages so determined. The residual hull girder strength indices can then be determined and formulated in a closed expression associated with collision damages and ship length. The developed formulations will be useful to quickly calculate the hull collapse strength of double hull oil tankers immediately after collisions.
\end{abstract}

Keywords: Ship collision, collision impact damage, residual ultimate hull girder strength, double hull oil tanker, intelligent supersize finite element method

\section{INTRODUCTION}

In recent decades, the number of sailing ships navigating the seas and oceans has increased significantly. According to Tournadre (2014), from 1992 to 2002 maritime traffics have increased by $60 \%$ and continued to raise till 2012, with the exception of 2008-2009, when it remained almost constant due to the economic crisis. Whenever ships travel by sea, there is a risk of accidents such as fires, explosions, collision impacts or grounding, which may 
cause a loss of human life, environmental damage and economic loss. Among these, the risk of collision impact is one of the most serious. Collisions can have severe consequences, including in some cases the total loss of the ship. The ship structure can lose its hull girder strength partially or totally and may become unable to sustain the bending loads after collision. This collapse of hull girder may lead to a massive oil spill which eventually causes environmental pollutions.

Based on the above-mentioned scenario, it is of interest to study the residual strength of ship hulls after shipship collisions. Several methods for predicting the residual strength of damaged ship's hull due to collision impact have been proposed. For example, the analytical method (Smith 1977; Paik et al. 2013), the non-linear finite element method (Chen 1983), the idealised structural unit method (ISUM) (Ueda et al. 1984; Ueda et al. 1986; Paik and Pedersen 1996) and the intelligent supersize finite element method (ISFEM) (Hughes and Paik 2013; Magoga and Flockhart 2014).

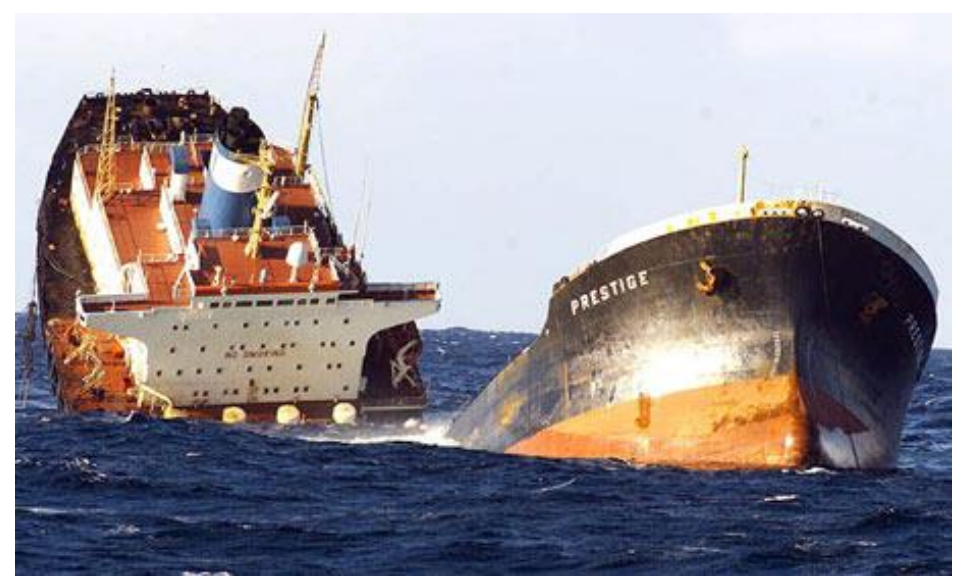

Fig. 1: The prestige oil tanker incident in 2002 is an example of hull girder collapse (https://globalvoicesonline.org/).

Many previous researchers have carried out studies on the consequences of a ship collision and have proposed methods to reduce the consequences (Paik and Thayamballi 1998; Zheng et al. 2007; Khan and Das 2008; Youssef et al. 2014; Kim et al. 2015; Youssef et al. 2015). A number of studies regarding hull impact and grounding aimed to establish a framework for the post-collision scenario (Hong and Amdahl 2008; Haris and Amdahl 2012; Tabri 2012; Obisesan et al. 2015). In concern of damage extent International Ship and Offshore Structures Congress reported on collision and grounding damage to assess local and global residual strength of ship structure after accidental events (ISSC 2009). Yet, in the current shipbuilding industry, most calculations used to achieve the safety criteria are defined distinctly by dealing with the worst possible scenario. The rules of the International Association of Classification Societies (IACS 2014), the American Bureau of Shipping (ABS 1995) and Det Norske Veritas (DNV 2004) distinctly define the post-collision impact damage scenarios. To investigate more realistic collision scenarios and the consequences of the ship impact damage, it is suggested that this assessment method could be improved by identifying the accidental damage scenarios using a probabilistic approach, by considering samples of all possible scenarios from historical data. The nature of ship collision impact damage is unclear and involves a variety of 
influencing parameters that are naturally probabilistic, and thus a probabilistic approach is necessary. Thus, such an approach is used in this present study to define a relevant set of ship damage scenarios by dealing with the influencing parameters of a ship's post-collision impact damage as random variables.

The approach is extended for the analysis of statistical features of simulation solutions. Diagrams, consisting of a combination of a few sets of probability density functions (PDFs) created from the simulation results, show the relationship with other variables from the ship. This approach, which compiles sets of PDF simulation results in terms of residual strength, allowed us to investigate the damage characteristics by establishing a co-relation of residual strength index (RSI) against ship length for different double hull oil tankers. The developed diagrams offer a new simplistic way for engineers and clients to estimate the residual strength of a damaged ship's values, without the need to perform a simulation.

Our objective is to investigate the statistical characteristics of damaged double hull oil tankers involved in shipship collision. The influencing parameters' historical data is statistically analysed in a probabilistic manner and several sets of damaged ship scenarios are extracted using a sampling technique from the developed PDF. Previously, several studies were conducted concerning ship hull impact and collision consequences analysis (Zhang and Suzuki 2006; Paik 2007; Ringsberg 2010; Pill and Tabri 2011). The longitudinal hull girder strength capacity of the hypothetical ships is calculated using ALPS/HULL (2016) ISFEM software. A relative probability function is generated from the results of the damaged ship's residual strength calculation. This is to establish a relationship between RSI and ship length for different double hull oil tankers and for the rapid prediction of the impact response associated with an oil tanker's hull cross-sectional area when subjected to collision impact damage.

\section{APPLIED METHOD}

The outline of the framework used in this study is illustrated in Figure 2. This procedure was inspired by the Paik's innovative method for the development of the R-D diagram (Paik et al. 2012). The last stage of the original procedure is revised for the statistical characteristic analysis that suits the objective of this study.

We begin this study by defining the ship's structural characteristics. Four double hull oil tankers have been used as the target structures and the principal dimensions are shown in Figure 3. The damage parameters are then identified to gather the historical data required and are then used for selection of the damage scenarios. At this stage, the gathered historical data are arranged and statistically analysed using the probabilistic approach, to ascertain the range of possible scenarios. The damaged parameter data are then developed into a PDF to extract sets of randomly selected damaged ship scenarios using the sampling technique. After creating the scenarios, the residual strength is calculated using ALPS/HULL software. The vertical bending moments in hogging and sagging are considered when calculating the longitudinal bending capacity of a ship's structure after a collision. The maximum moment capacity, also known as the ultimate bending moment, for each scenario is compared with the intact ultimate bending moment of the same target structure. The comparison is presented in terms of the RSI and finally, the RSIs for each loading type are statistically analysed using the PDF to perform the statistical characteristic analysis. After these procedures are completed, the developed diagrams from the statistical analysis are ready to be evaluated. 


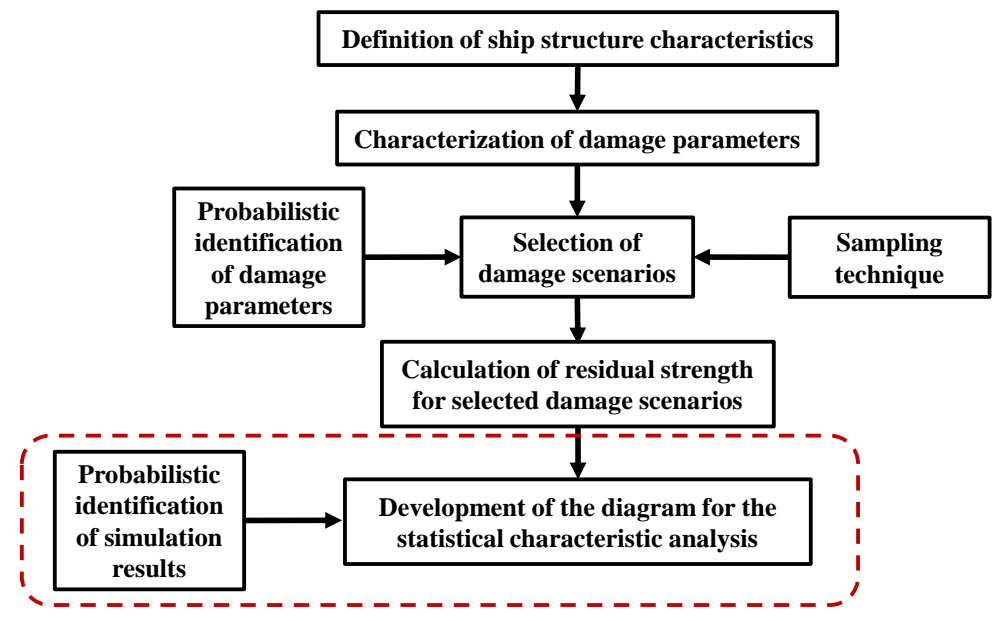

Fig. 2: The general procedure for the development of the R-D diagram (Paik et al. 2012).

\section{TARGET STRUCTURE}

\subsection{Principal dimension}

Although there are various types of vessels or merchant ships sailing the oceans, this study focused on oil tankers due to the higher risk related to oil spills. Oil tankers are used to carry large volumes of oil through international ship lanes. The accidental oil spills can release a significant amount of oil if the inner shell and the outer shell are damaged, leading to disastrous environmental pollution and economic lose. The collision between the Very Large Crude Carrier (VLCC) 'Atlantic Empress' and the fully laden supertanker 'Aegean Captain' on 19 July 1979 was one of the most severe ship-ship collisions and lessons were well-learned by the industry. During a tropical rainstorm, the Empress sank after spilling 288,000 metric tonnes of crude oil into the Caribbean Sea and causing 27 fatalities (Horn and Neal 1981). While the safety of human life is always important, the safety of the environment is also a paramount consideration these days.

Therefore, previous studies have utilized various type of oil tankers as their models or target structures (Garrè and Rizzuto 2012; Santos and Soares 2008; Tavakoli et al. 2012; Taylor et al. 2015; Villavicencio et al. 2013a; Zhang et al. 2015). In this study, four types of double hull oil tankers (i.e. Panamax, Aframax, Suezmax and VLCC) are considered when performing the statistical characteristics analysis of the damaged ships. Figure 3 shows the mid-ship section designs of the four oil tankers in which L is the ship's length between perpendiculars, B is the ship's breadth and D is the ship's depth. 


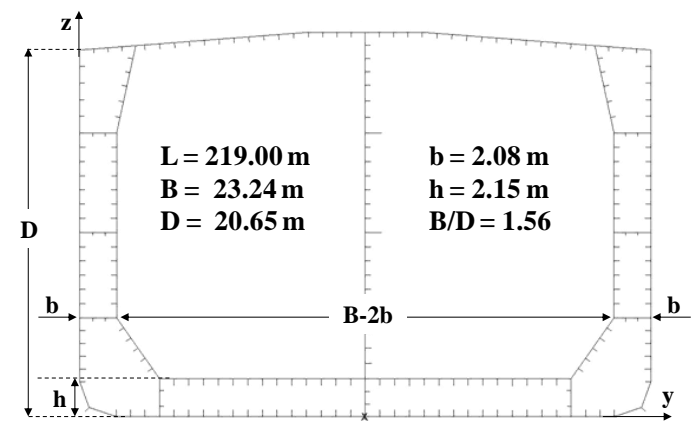

(a) Panamax

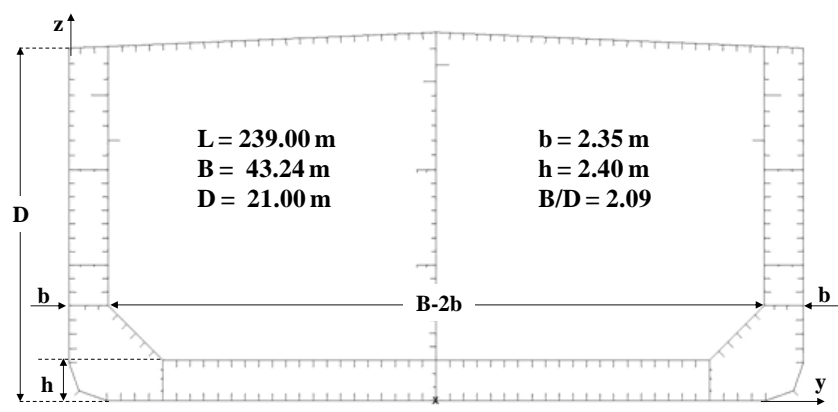

(b) Aframax

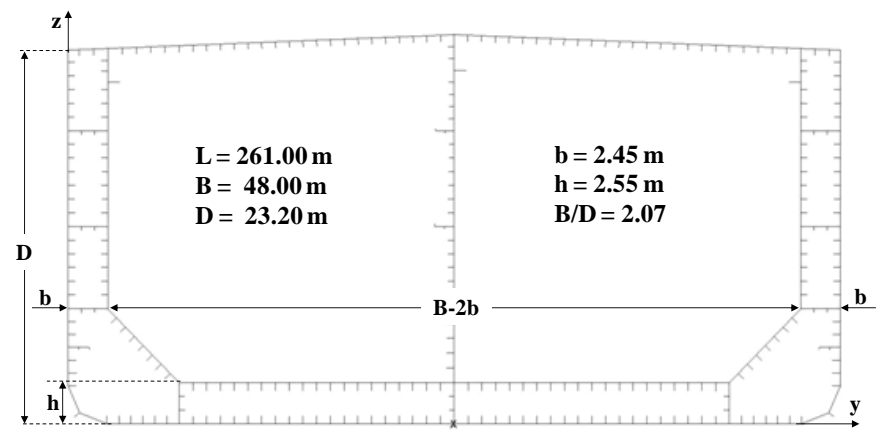

(c) Suezmax

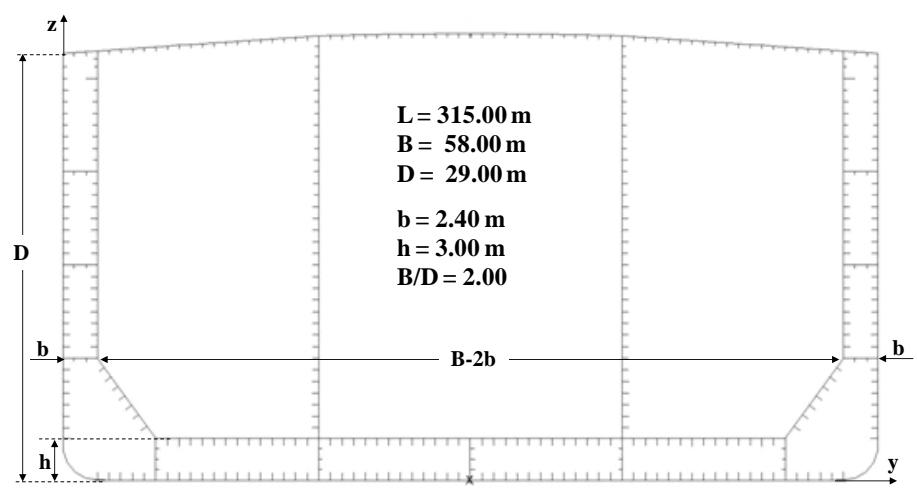

(d) VLCC

Fig. 3: The mid-ship section configuration with the principal dimensions of the four types of hypothetical double hull oil tanker. 


\subsection{Post-collision impact damage ship parameters}

As illustrated in Figure 2, after the ship's structural characteristics, including its geometry, dimensions and material properties are defined, it is important to identify the parameters that govern the structural damage from post-collision impact. For this purpose, an extensive analysis of the damaged ship is used to characterise the scenario parameters that can affect the damage pattern in the target vessels. These parameters are as follows:

- $\quad$ vertical impact location $\left(X_{\mathrm{V}} / \mathrm{D}\right)$,

- damage penetration $\left(X_{b} / B\right)$,

- $\quad$ striking ship's bulbous bow height $\left(\mathrm{R}_{\mathrm{V}}\right)$, and

- $\quad$ striking ship's bulbous bow length $\left(\mathrm{R}_{\mathrm{L}}\right)$.

The vertical impact location $\left(\mathrm{X}_{\mathrm{V}} / \mathrm{D}\right)$ is a dimensionless input defined as a difference in vertical direction (depth) between the struck ship's baseline and the baseline of the striking ship $\left(\mathrm{X}_{\mathrm{V}}\right)$ over the depth (D) of the target structure. This difference can be caused by a difference in ship size, displacement or a ship's draft due to the load carried by each ship during the collision. Next parameter is the damage penetration $\left(\mathrm{X}_{\mathrm{b}} / \mathrm{B}\right)$, defined as a dimensionless value from the struck ship's outer side shell to the tip of the striking ship's bulbous bow penetrating the struck ship $\left(\mathrm{X}_{\mathrm{b}}\right.$ ) compared to the breadth (B) of the struck ship. Upon the ship-ship collision, the striking ship's penetration of the body of the struck ship usually depends on the ship's speed, the collision angle and the location of the impact. However, it is assumed in this study that the bows of all striking ships are rigid and penetrate the midhull section of struck ships perpendicularly.

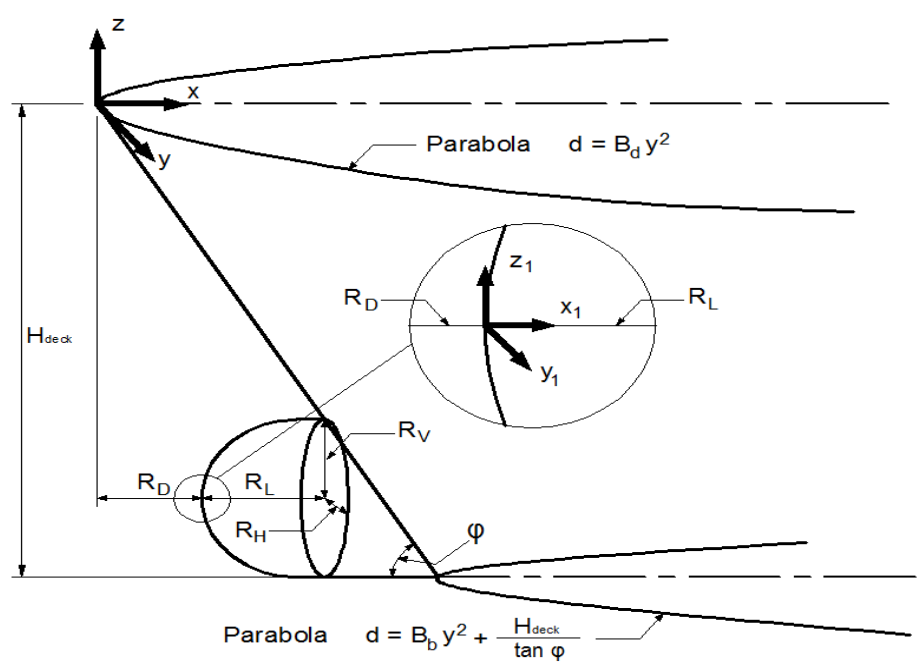

Fig. 4: Lützen's bow model (Lützen 2001).

In addition, the bow shape of the striking ship is important because it determines the volume of the structure that is presumed to be damaged during the collision (Rawson et al. 1998). Although the refined bow models are more realistic, they are difficult to analyse (Wang et al. 2002). Based on the literature review, several bulbous bow 
shapes of striking ships have been modelled and used in impact test experiments, in particular the conical shape with different lengths and spreading angles (Wang et al. 2000; Lee et al. 2001; Paik et al. 2005) and the knife edge (Villavicencio et al. 2013b). Additionally, Zhang (1999) and Lützen (2001) modelled the bulb as an elliptic parabola. The Lützen model chosen in this study suggested a striking bow shape that describes the whole ship bow portion.

The 2-dimensional model parameters were considered for the striking ship's bow. Based on the model shown in Figure 4, only $R_{V}$ and $R_{L}$ were used to create the striking ship's bow. Equations 3.1 and 3.2 were used to calculate $R_{V}$ and $R_{L}$ respectively from Lützen (2001). In addition, Lützen defined all of the parameters as a function of the ship's dimensions; that is, if the length, breadth and depth or deck height of the striking ship is known, the forward bow portion can be determined.

$$
\begin{aligned}
& \mathrm{R}_{\mathrm{V}}=0.243 \mathrm{H} \\
& \mathrm{R}_{\mathrm{L}}=0.0351 \mathrm{~L}
\end{aligned}
$$

where, $\mathrm{L}$ is the striking ship's length and H is the striking ship's depth.

\section{SCENARIO SELECTION}

The selected scenarios are created probabilistically to include all possible and relevant scenarios. In the probabilistic approach, a relevant set of damage scenarios is identified and selected using the detailed method proposed by Youssef et al. (2014), with modification to suit the study, as shown in Figure 5. Each parameter is statistically analysed to estimate the occurrence probability and to represent the probability levels of occurrence for each scenario.

In practice, numerous parameters are related to a ship's damage and each scenario is distinguished by damage variables and probability amplitude. Therefore, the identification of the damage variables is an important step in describing the scenarios. Section 3 discussed some parameters governing the post-collision impact damage.

A historical database of ship damage and accidents are required for the following steps. The sources of incidents databases are compiled by accidental investigation boards (i.e. flag states) under the responsibility of the national maritime authorities of different countries and some other publicly accessible data such as the Centre For Tankship Excellence (C4TX 2015).

Using the available accident database, each variable is described by defining its range and variability by creating a histogram of the data. The histogram is formulated by PDF to evaluate the compatibility for different selective parameters. Figure 6 are examples of PDFs the damaged ship's parameters. 


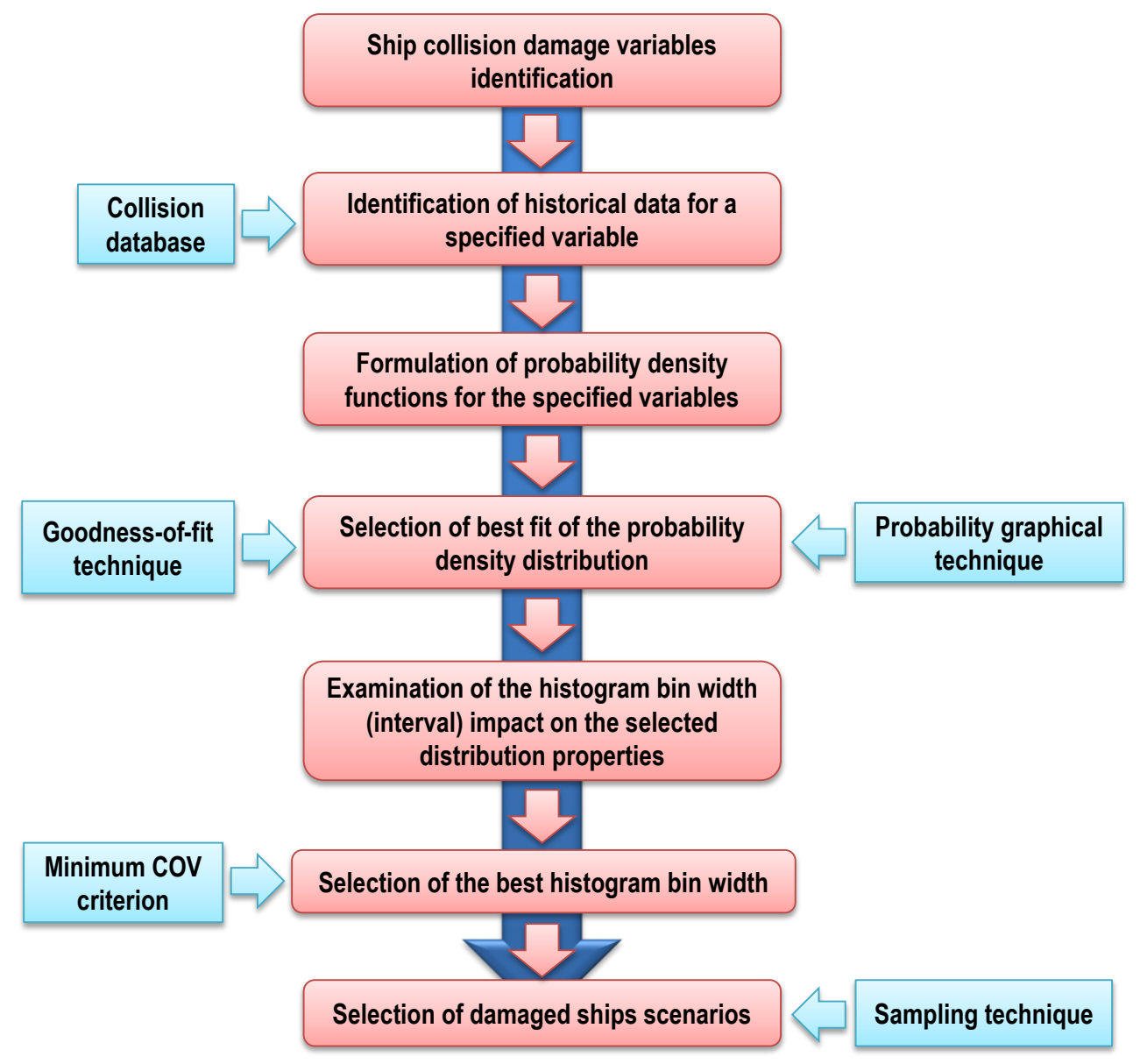

Fig. 5: The flow chart detailing the selection of scenario adapted from Youssef et al. (2014), the proposed method for collision scenario selection.

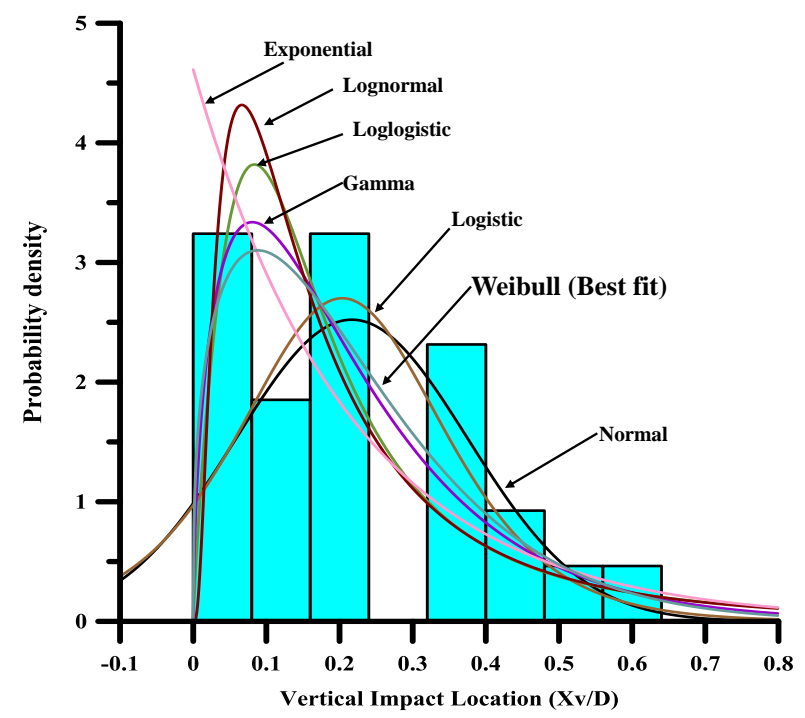

(a) PDF for vertical impact location

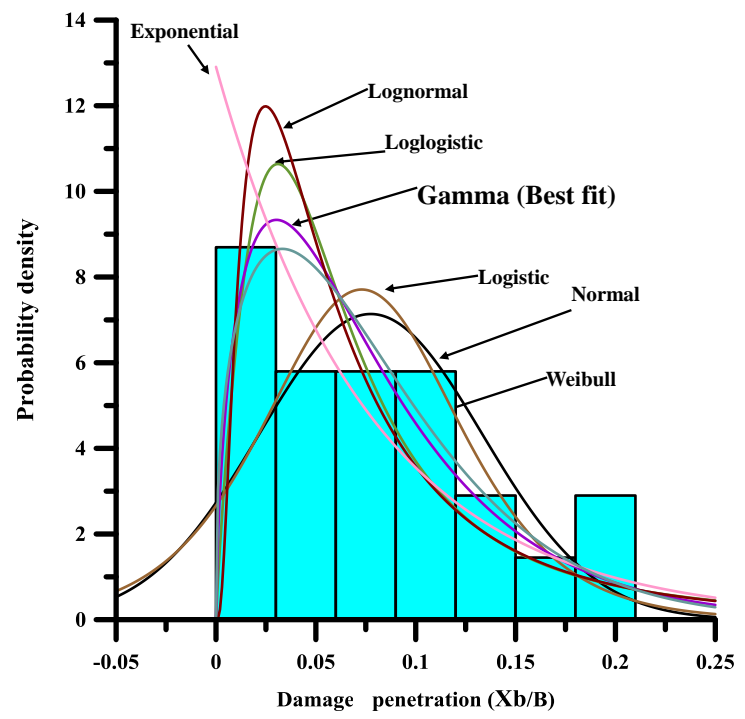

(b) PDF for damage penetration 


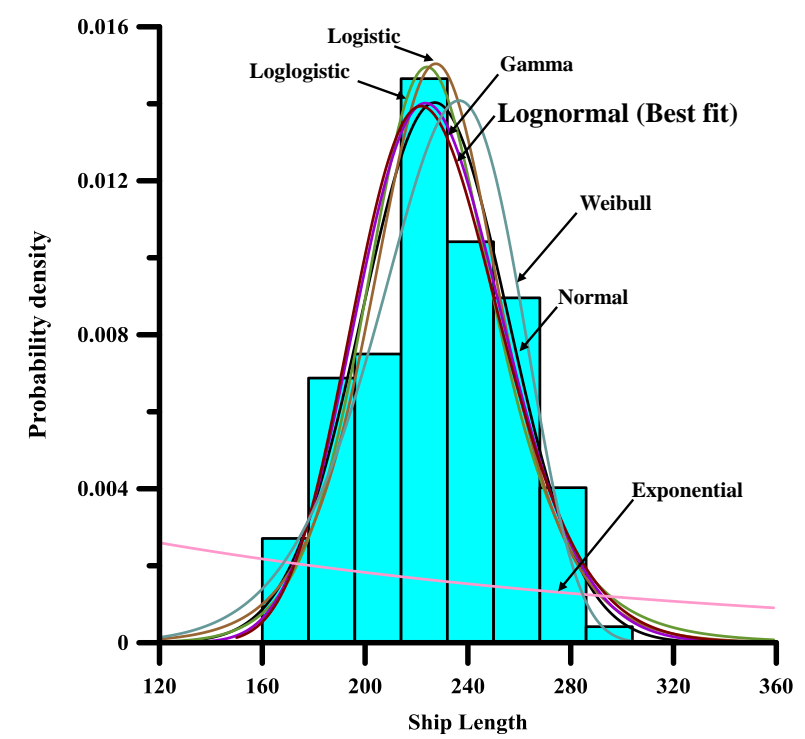

(c) PDF for ship length

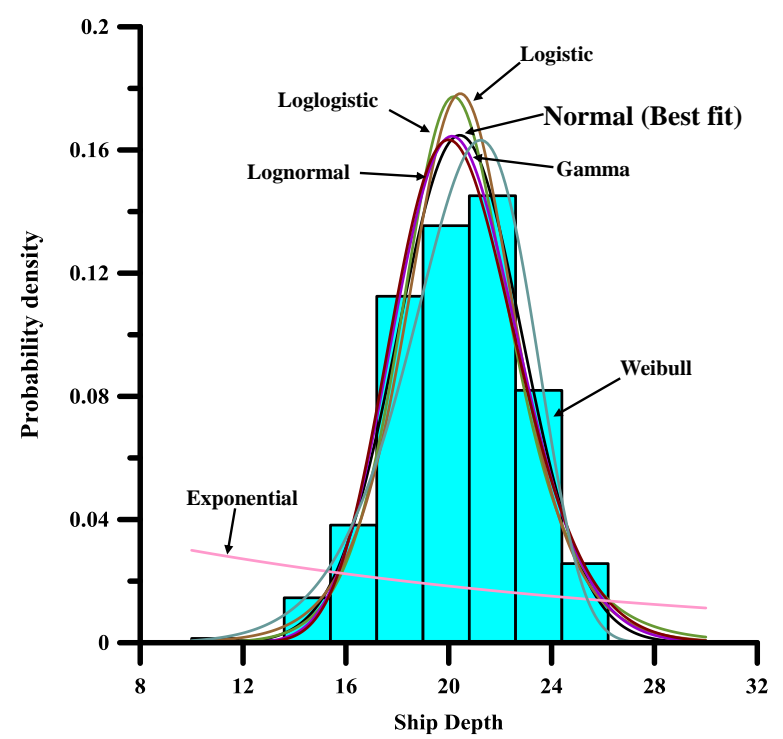

(d) PDF for ship depth

Fig. 6: The probability density distribution function (PDF) of the damaged ship's parameters.

Next, a Goodness-of-Fit (GOF) test is performed to measure the compatibility of a random sample with some of the theoretical probability distribution functions. To avoid the risk of assuming that the data following a specific distribution, the Kolmogorov-Smirnov (K-S) test (Chakravarty et al. 1967) is used to determine the best PDF representing the original gathered data. The K-S test (Chakravarty et al. 1967) is a widely used GOF test, which uses the maximum absolute difference between the distribution functions of the samples (Lopes et al. 2007). For a given sample (n), the K-S test statistic ( $D_{n}$ ) is calculated using Equation 4.1, where $\sup _{x}$ is the supremum of the set of distances. The calculated statistic for each variable is shown in Table 1.

$$
D_{n}=\sup _{x}\left|F_{n}(x)-F(x)\right|
$$

Table 1. The GOF test (K-S) statistics for various PDFs.

\begin{tabular}{|c|c|c|c|c|}
\hline \multirow{2}{*}{ Distribution function } & \multicolumn{3}{|c|}{ PDF test statistics for the damage parameters } \\
\cline { 2 - 5 } & $\begin{array}{c}\text { Vertical impact } \\
\text { location }\left(\mathrm{X}_{\mathrm{V}} / \mathrm{D}\right)\end{array}$ & $\begin{array}{c}\text { Damage } \\
\text { Penetration }\left(\mathrm{X}_{\mathrm{b}} / \mathrm{B}\right)\end{array}$ & \multicolumn{2}{|c|}{ Striking ship } \\
\cline { 4 - 5 } & 0.11862 & 0.15015 & 0.10928 & 0.07772 \\
\hline Weibull & 0.12684 & 0.11829 & 0.52171 & 0.51234 \\
\hline Exponential & 0.14654 & 0.12131 & 0.08812 & 0.05771 \\
\hline Normal & 0.13459 & 0.16533 & 0.08160 & 0.07142 \\
\hline Lognormal & 0.13532 & 0.11777 & 0.08488 & 0.06726 \\
\hline Gamma & 0.15603 & 0.14372 & 0.10066 & 0.07227 \\
\hline Logistic & 0.14742 & 0.17474 & 0.08763 & 0.08348 \\
\hline Log-Logistics & & & & \\
\hline
\end{tabular}


Once the best PDF is selected, the effect of the histogram bin width (interval) on the distribution properties of the gathered historical data are studied and compared. The histogram bin width usually has a significant effect on the data distribution properties. Paik et al. (2003) suggested the 'minimum COV criterion', in which the values of distribution parameters (i.e. mean value and coefficient of variation (COV)) are used to decide the best histogram bin width. Thus, the minimum COV guarantees that the degree of variation between the probability distribution and the data will be the smallest that can be achieved at the minimum standard deviation (i.e. minimum data spreading) and maximum mean values. Therefore, the bin width that gives the largest mean value and the smallest COV is selected for each parameter. Figure 7 shows the result of the calculation for the mean and the COV, to examine the effect of the histogram bin width (interval) on the distribution parameters for the selected PDFs on each parameter.

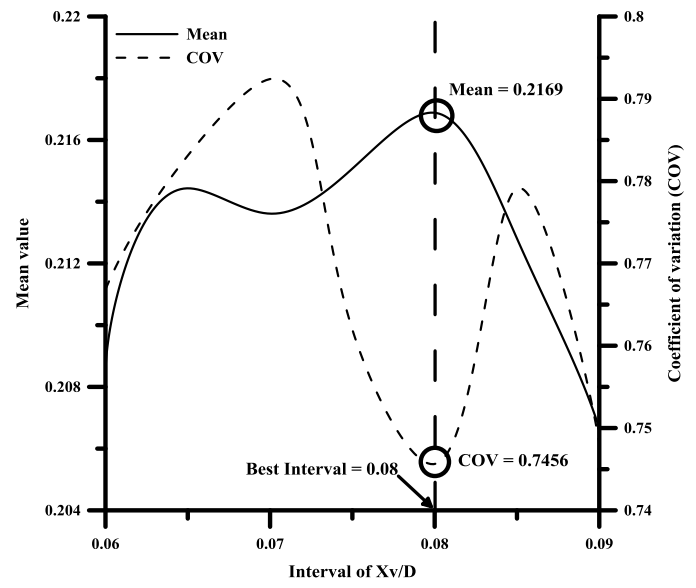

(a) PDF for vertical impact location

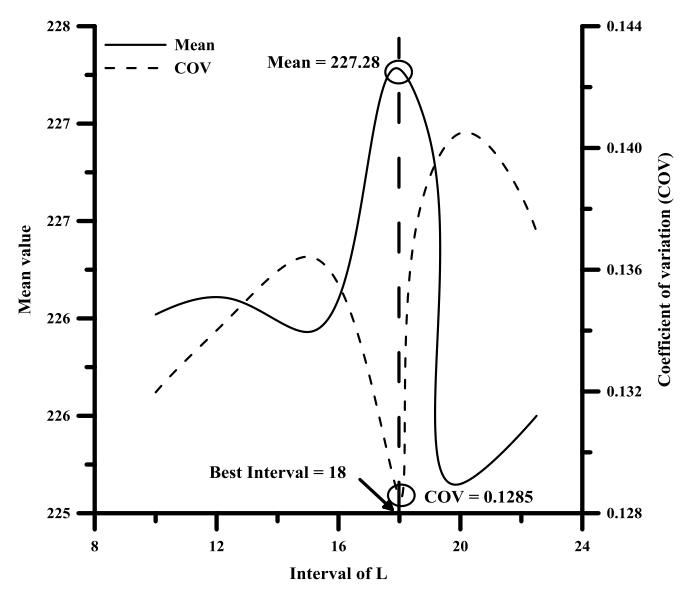

(c) PDF for striking ship length

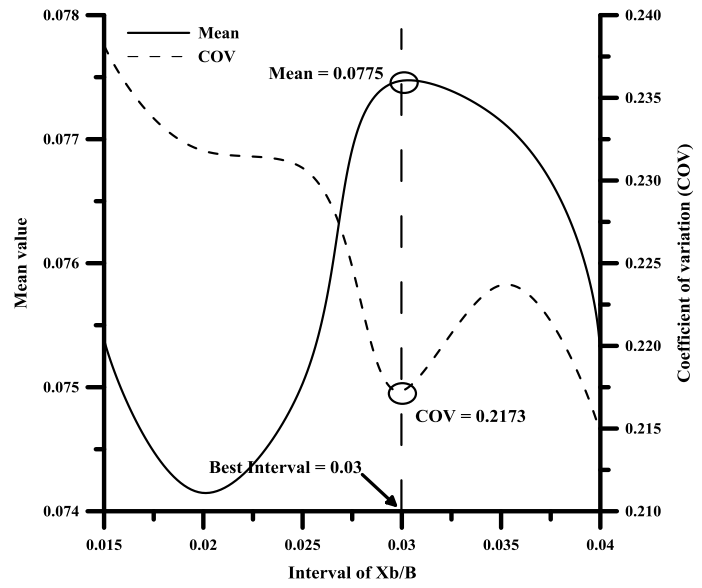

(b) PDF for damage penetration

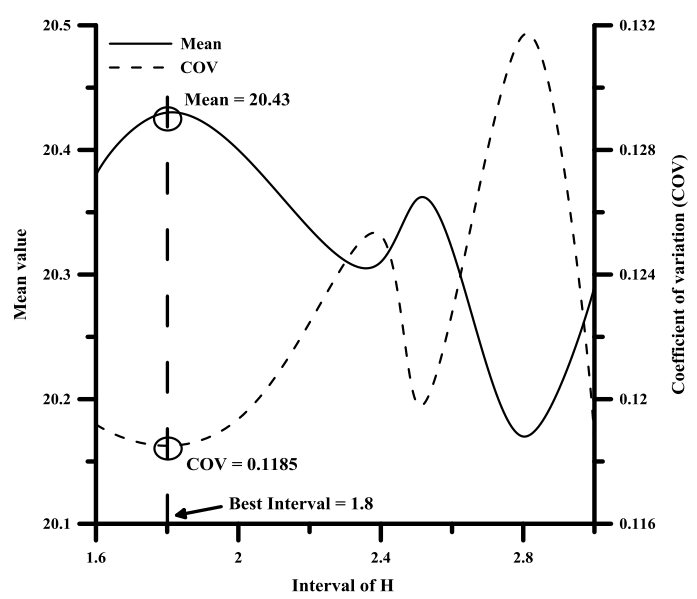

(d) PDF for striking ship depth

Fig. 7: The effect of histogram bin width (interval) on the mean and COV for the damaged ship's parameters. 


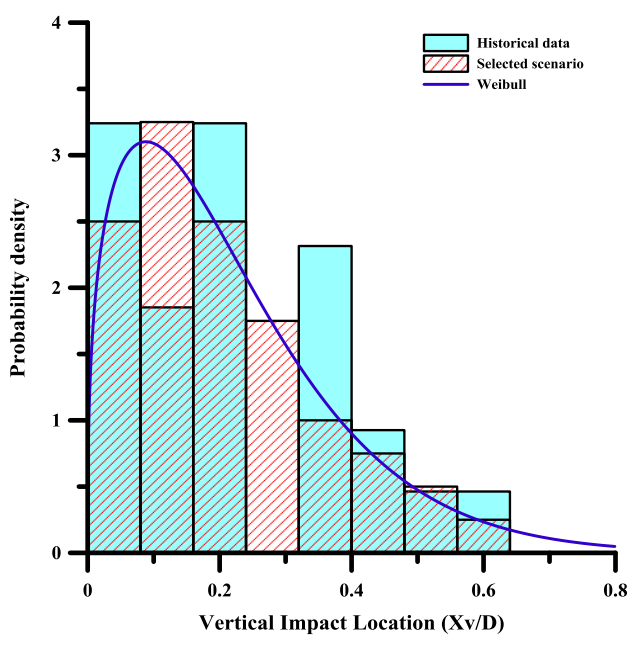

(a) PDF for vertical impact location

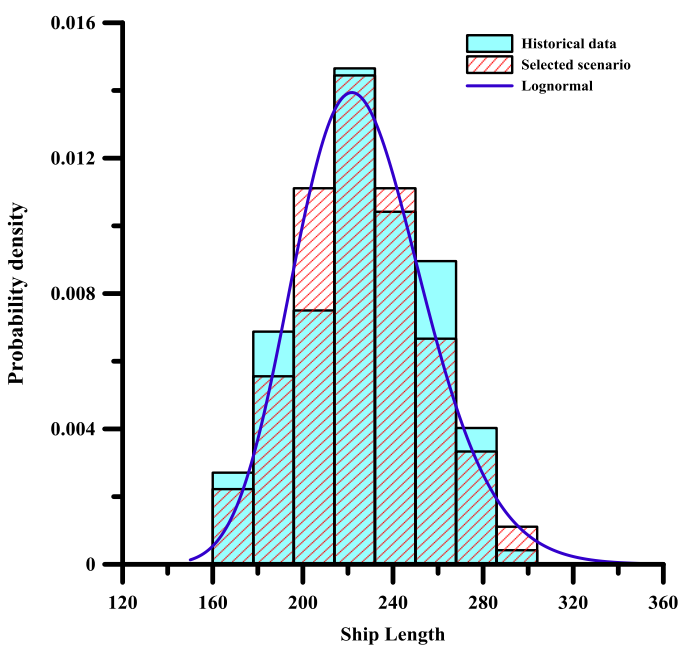

(c) PDF for striking ship length

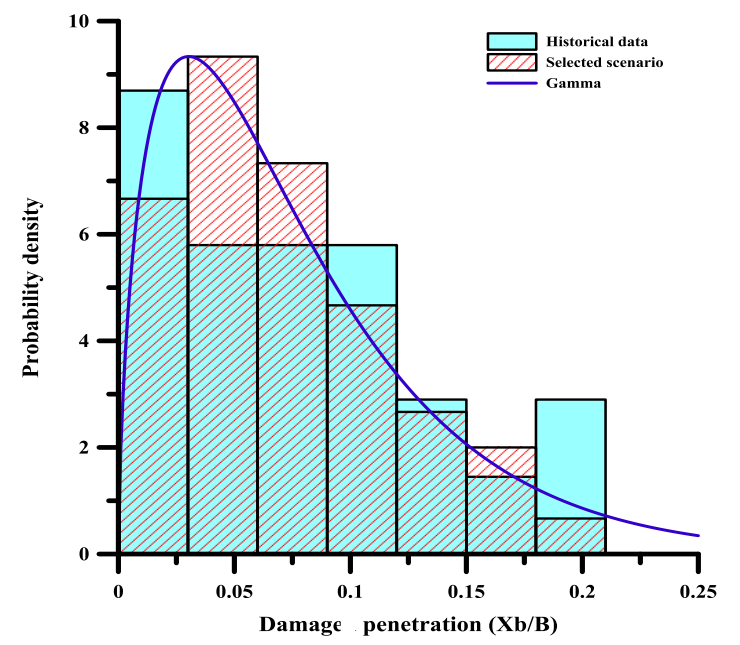

(b) PDF for damage penetration

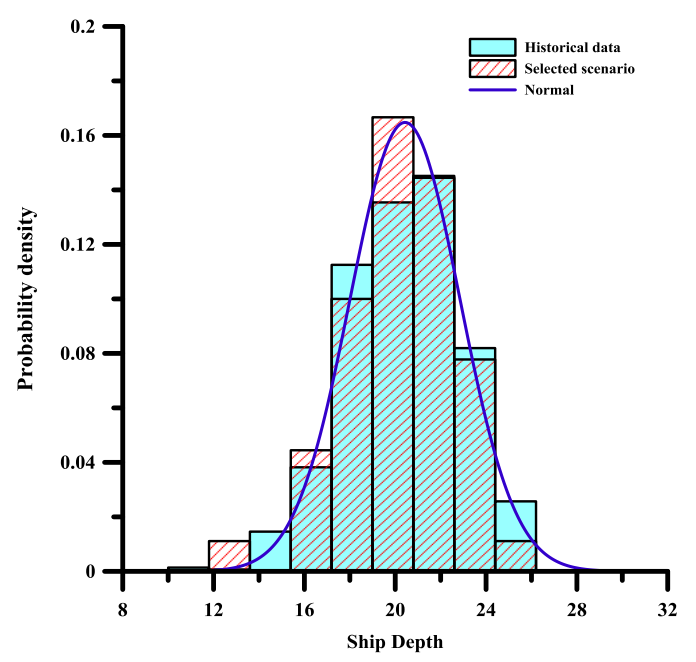

(b) PDF for striking ship depth

Fig. 8: The selected PDF for the damaged ship's parameters.

After assigning the best histogram bin width (interval) for each variable, the PDFs are formulated to represent the original data, as shown in Figure 8.

Although a huge number of possible collision scenarios may be relevant, it is not practical to consider all of them. At this point, a sampling technique is used to select 50 damaged ship scenarios. Accordingly, the 50 damaged ship scenarios will be randomly selected, consisting of vertical impact location ( $\left.\mathrm{X}_{\mathrm{V}} / \mathrm{D}\right)$, damage penetration $\left(\mathrm{X}_{\mathrm{b}} / \mathrm{B}\right)$, ship length and ship depth, which are then used to model the damaged ships for the simulation. Table 2 lists the randomly selected scenarios previously presented. Figure 8 also illustrates the comparisons of the selected PDFs that fit the historical data and the histogram of the selected 50 scenarios for each ship's post-collision impact damage parameters. 
Table 2: 50 scenarios selected.

\begin{tabular}{|c|c|c|c|c|}
\hline Sc. no & $\begin{array}{l}\text { Vertical impact location } \\
\qquad\left(\mathrm{X}_{\mathrm{v}} / \mathrm{D}\right)\end{array}$ & $\begin{array}{l}\text { Damage penetration } \\
\qquad\left(\mathrm{X}_{\mathrm{b}} / \mathrm{B}\right)\end{array}$ & Ship length (m) & Ship depth (m) \\
\hline 1 & 0.1184 & 0.0663 & 227.2 & 20.52 \\
\hline 2 & 0.4561 & 0.0438 & 212.8 & 19.30 \\
\hline 3 & 0.3320 & 0.1374 & 261.9 & 23.09 \\
\hline 4 & 0.0929 & 0.0567 & 221.5 & 20.04 \\
\hline 5 & 0.2805 & 0.0418 & 211.3 & 19.17 \\
\hline 6 & 0.1733 & 0.0545 & 220.0 & 19.93 \\
\hline 7 & 0.1962 & 0.0638 & 225.7 & 20.40 \\
\hline 8 & 0.2301 & 0.1048 & 246.8 & 22.04 \\
\hline 9 & 0.3643 & 0.0743 & 231.6 & 20.87 \\
\hline 10 & 0.1588 & 0.0523 & 218.6 & 19.80 \\
\hline 11 & 0.0545 & 0.1307 & 258.8 & 22.89 \\
\hline 12 & 0.4278 & 0.0136 & 177.2 & 15.79 \\
\hline 13 & 0.2589 & 0.0260 & 197.3 & 17.87 \\
\hline 14 & 0.1807 & 0.1092 & 248.9 & 22.20 \\
\hline 15 & 0.0478 & 0.1917 & 291.9 & 24.72 \\
\hline 16 & 0.2212 & 0.1139 & 251.1 & 22.35 \\
\hline 17 & 0.4038 & 0.0358 & 206.6 & 18.74 \\
\hline 18 & 0.3474 & 0.0299 & 201.3 & 18.25 \\
\hline 19 & 0.6026 & 0.0338 & 204.9 & 18.59 \\
\hline 20 & 0.4907 & 0.0863 & 237.8 & 21.37 \\
\hline 21 & 0.0261 & 0.1246 & 256.0 & 22.70 \\
\hline 22 & 0.0610 & 0.0689 & 228.6 & 20.64 \\
\hline 23 & 0.2126 & 0.1450 & 265.4 & 23.32 \\
\hline 24 & 0.0802 & 0.0590 & 222.9 & 20.16 \\
\hline 25 & 0.2694 & 0.0896 & 239.5 & 21.49 \\
\hline 26 & 0.1382 & 0.0180 & 186.6 & 16.81 \\
\hline 27 & 0.0992 & 0.0158 & 182.6 & 16.39 \\
\hline 28 & 0.5359 & 0.0831 & 236.2 & 21.24 \\
\hline 29 & 0.1056 & 0.0200 & 189.8 & 17.14 \\
\hline 30 & 0.1250 & 0.0771 & 233.1 & 20.99 \\
\hline 31 & 0.0177 & 0.0931 & 241.2 & 21.63 \\
\hline 32 & 0.0409 & 0.1007 & 244.9 & 21.90 \\
\hline 33 & 0.2922 & 0.1640 & 274.6 & 23.88 \\
\hline 34 & 0.0337 & 0.0241 & 195.0 & 17.66 \\
\hline
\end{tabular}




\begin{tabular}{|c|c|c|c|c|}
\hline Sc. no & $\begin{array}{c}\text { Vertical impact location } \\
\left(\mathrm{X}_{\mathrm{v}} / \mathrm{D}\right)\end{array}$ & $\begin{array}{c}\text { Damage penetration } \\
\left(\mathrm{X}_{\mathrm{b}} / \mathrm{B}\right)\end{array}$ & Ship length $(\mathrm{m})$ & Ship depth $(\mathrm{m})$ \\
\hline 35 & 0.1120 & 0.0800 & 234.6 & 21.12 \\
\hline 36 & 0.2489 & 0.0221 & 192.6 & 17.41 \\
\hline 37 & 0.1518 & 0.0614 & 224.3 & 20.28 \\
\hline 38 & 0.0075 & 0.0398 & 209.8 & 19.03 \\
\hline 39 & 0.0866 & 0.0501 & 217.2 & 19.68 \\
\hline 40 & 0.3178 & 0.0459 & 214.3 & 19.43 \\
\hline 41 & 0.2393 & 0.0319 & 203.1 & 18.42 \\
\hline 42 & 0.1884 & 0.0480 & 215.7 & 21.76 \\
\hline 43 & 0.1315 & 0.0968 & 243.0 & 12.71 \\
\hline 44 & 0.3829 & 0.0112 & 166.5 & 20.75 \\
\hline 45 & 0.0675 & 0.0715 & 230.1 & 18.89 \\
\hline 46 & 0.2043 & 0.0378 & 208.2 & 24.24 \\
\hline 47 & 0.3046 & 0.1765 & 281.4 & 23.58 \\
\hline 48 & 0.1660 & 0.1537 & 269.5 & 22.52 \\
\hline 49 & 0.1450 & 0.1190 & 253.4 & 18.07 \\
\hline 50 & 0.0739 & 0.0280 & 199.3 & \\
\hline
\end{tabular}

\section{ISFEM SIMULATION}

\subsection{Modelling}

The collapse of a ship hull girder is catastrophic. This is critical in a ship already damaged from an accident such as a collision or grounding (i.e. post-accident collapse). In this study, the calculation of the girder's strength capacity is required for all intact and damaged target structure models subjected to ship-ship collision. The reduction in the strength capacity of the damaged ship's hull structure is presented in terms of the RSI, which is based on the ultimate longitudinal hull girder strength (i.e. the ultimate bending moment of the damaged ship's hull over the ultimate bending moment of the intact ship's hull). Equation 5.1 defines the RSI $_{i}$ for the impact damaged and intact cross-sections of the $i^{\text {th }}$ impact damaged ship scenario, where $M_{\mathrm{I} i}$ and $M_{\mathrm{D} i}$ are the ultimate bending moments for the intact and the damaged hull cross-sections, respectively.

$$
\text { (Residual strength index) } \mathrm{RSI}_{i}=\frac{M_{\mathrm{D} i}}{M_{\mathrm{I} i}}
$$

Various methods have been developed to calculate the ship ultimate strength, as mentioned previously. Of those methods, the ALPS/HULL (ALPS/HULL, 2016) progressive hull girder collapse analysis program, based on the ISFEM, is applied for the simulations. To clarify the accuracy of the ISFEM, a benchmark study of various analysis 
methods was carried out (ALPS/HULL, 2016) showing that ALPS/HULL can give reasonable results with efficient computational costs. Hughes and Paik (2013) provide a more detailed summary of the ALPS/HULL theory.

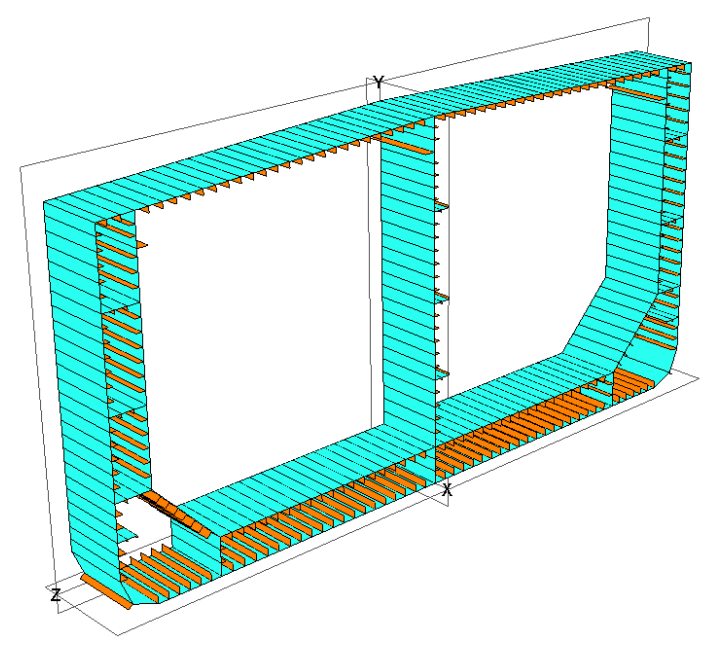

(a) Intact cross-section

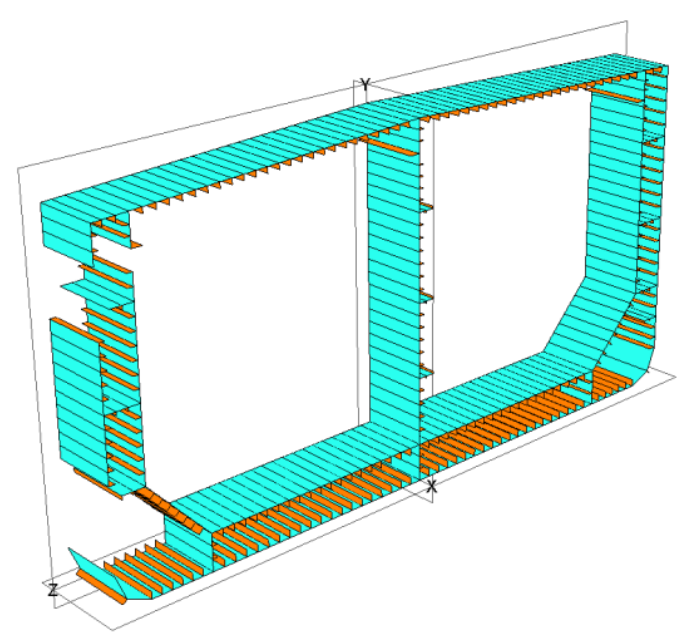

(b) Damaged cross-section (Sc.38)

Fig. 9: Samples of the ALPS/HULL ISFEM for the target Suezmax double hull oil tanker in the intact and damaged condition.

As previously mentioned, based on the 50 damaged ship scenarios obtained, a damaged ship is identified in terms of the vertical impact location $\left(\mathrm{X}_{\mathrm{V}} / \mathrm{D}\right)$ and the size of the structural damage by the striking ship's bulbous bow in the direction of the target structure's depth (D), and the damage penetration $\left(\mathrm{X}_{\mathrm{b}} / \mathrm{B}\right)$ in the direction of the struck ship's breadth (B). ALPS/HULL (2016) is used to model the target ship's hull cross-sections in both the intact and the damaged condition for each scenario. When a ship's structure is damaged in an accident, the damaged structural elements may not contribute to the global ship strength. The damaged elements should thus be eliminated from the strength calculations by removing them from the relevant part of the ship's cross-section. This so-called 'damaged element removal method' has been used in several related studies (Paik et al. 2012; Kim et al. 2013; Kim et al. 2014; Youssef et al. 2015) and is used here to model the hull damage in each case. Figure 9 shows samples of the ALPS/HULL ISFEM for the target Suezmax double hull oil tanker in both the intact and the damaged conditions. 


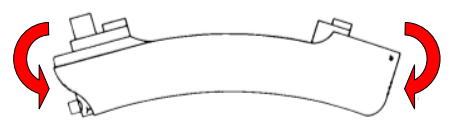

Hogging, $\mathrm{M}_{\mathrm{V}}(+)$

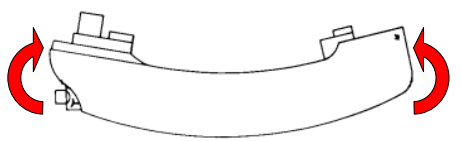

Sagging, $\mathbf{M}_{\mathbf{V}}(-)$

Fig. 10: The sign convention of the direction for longitudinal bending moment

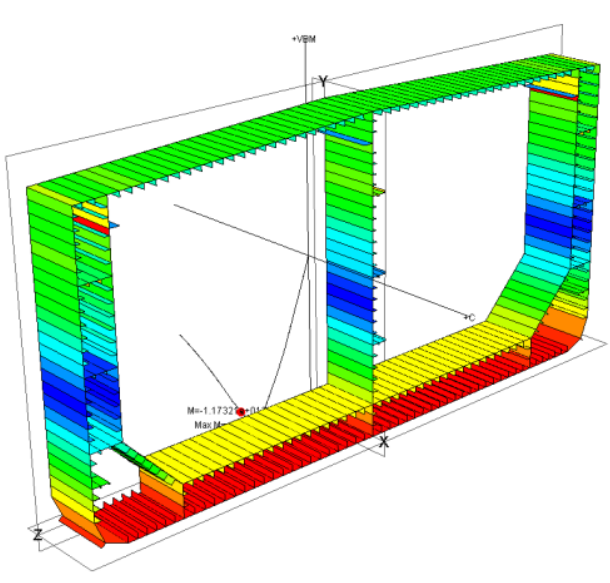

(a) Intact cross-section

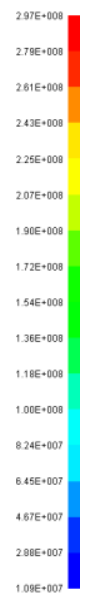

Fig. 11: Samples of the ALPS/HULL ultimate longitudinal strength calculation results in terms of the von Mises stress distributions for intact and damaged cross-sections under a sagging vertical bending moment

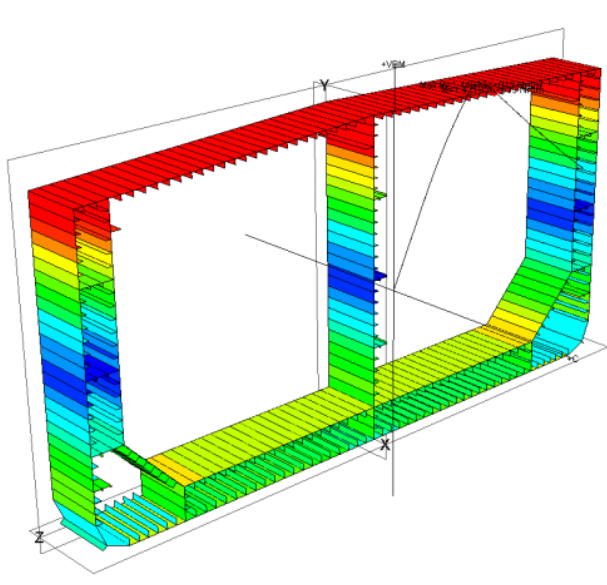

(a) Intact cross-section
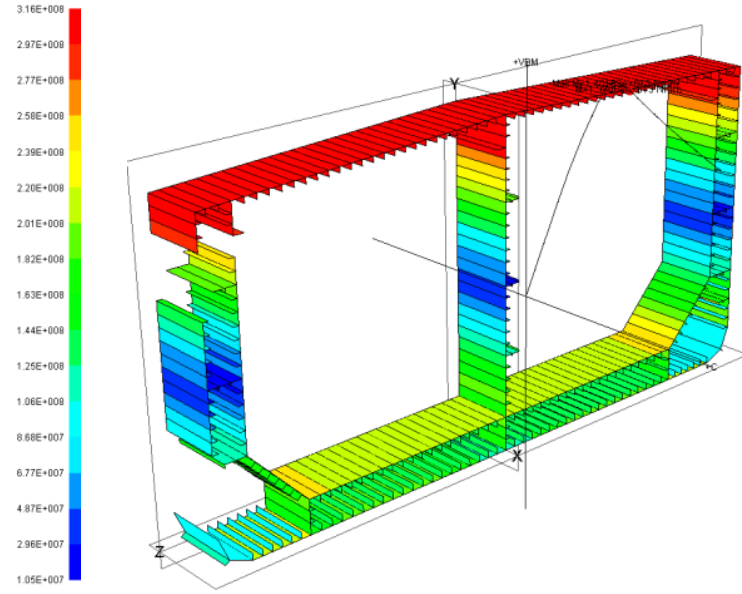

b) Damaged cross-section

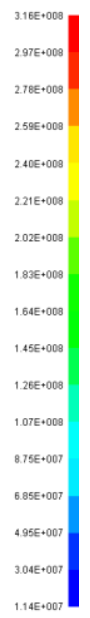

Fig. 12: Samples of the ALPS/HULL ultimate longitudinal strength calculation results in terms of the von Mises stress distributions for intact and damaged cross-sections under a hogging vertical bending moment 


\subsection{Simulation work}

Using the ALPS/HULL program, the ultimate longitudinal strength for both the intact and the damaged crosssections in individual scenarios is analysed only for the pure vertical bending moment under hogging and sagging conditions. Based on the analysis, the horizontal bending moment is not considered in this study. Figure 10 shows the sign convention used for the bending moment conditions. In the simulation, an average structural initial imperfection of plate and stiffener members is considered (Paik and Thayamballi 2003). Moreover, the target structures (i.e. intact and damaged) are assumed to be in the upright position. This assumption is based on the following:

1) The damaged ships have not lost any cargo or are not flooding right after the collision,

2) During salvage or towing for repair, the damaged ship is upright, and

3) To make a comparison with the intact ship, which is originally calculated to be in the upright position, it is necessary to consider the upright position for the damaged ship.

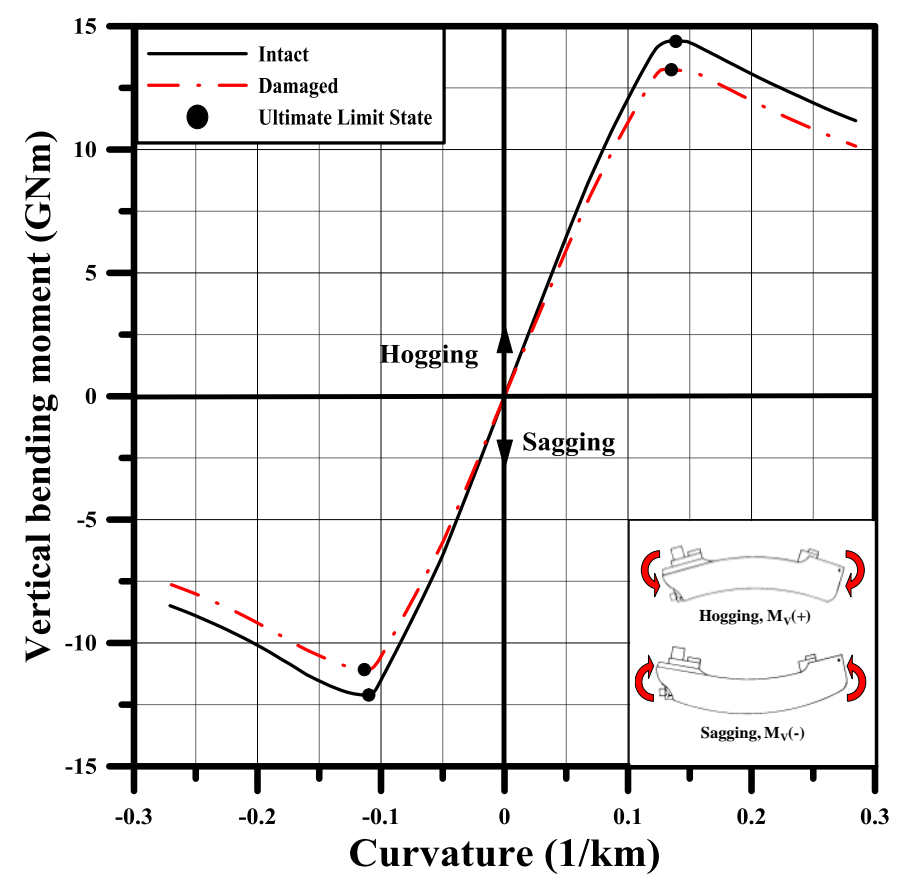

(a) Major damage (Suezmax Scenario 48) 


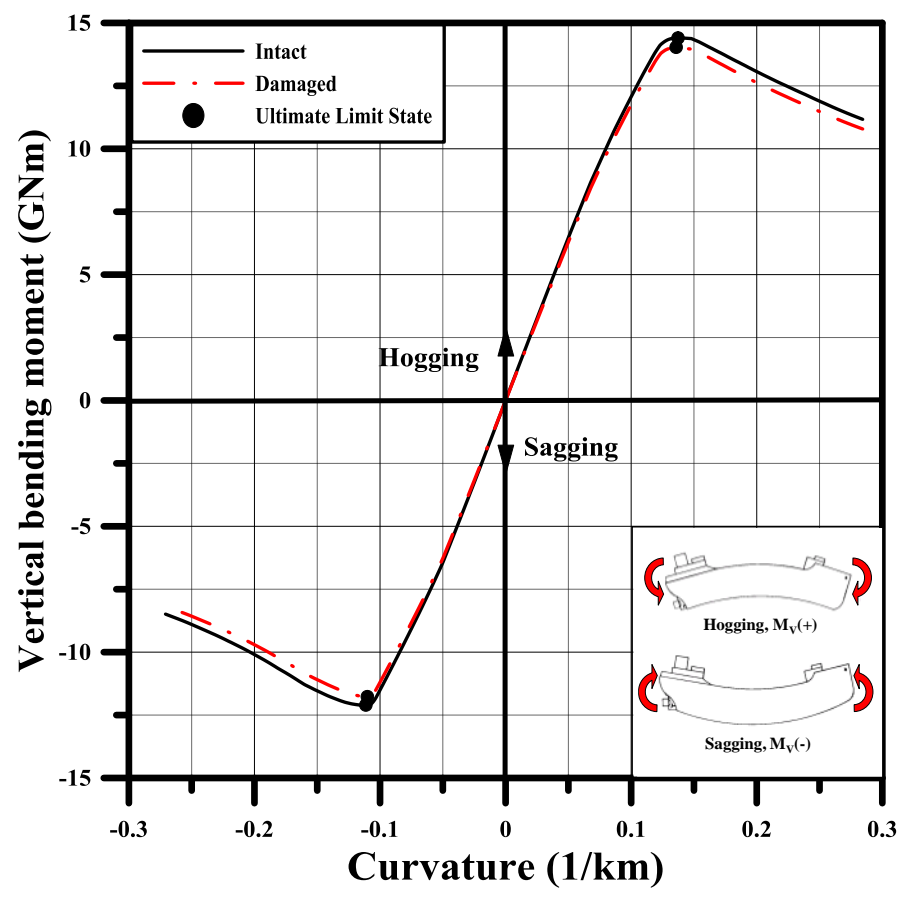

(b) Moderate damage (Suezmax Scenario 38)

Fig. 13: The moment-curvature relationships for intact and damage scenarios under a pure vertical bending moment.

Figure 11 shows samples of the analysis results in terms of the von Mises stress distributions at the ultimate limit state for intact and damaged cross-sections under a pure hogging vertical bending moment. Figure 12 shows the corresponding results for a pure sagging vertical bending moment. The moment-curvature curves for the target structure, developed as a result of the calculations for intact and damaged scenarios (i.e. cases of major and minor damage), are shown in Figure 13.

With regards to Figure 13, in the case of major damage, it can be seen that the residual strength is significantly lower than the moderate damage. This is expected as the residual ultimate longitudinal strength decreases as the extent of damage increases. At the ultimate limit state, the curvature of the intact hull section under vertical bending is observed to be smaller (e.g. 16\% for Suezmax) for sagging than for hogging. This is also expected, as the bottom structure is believed to be more redundant than the deck structure. Based on the above results, Equation 5.1 is then used to calculate the residual ultimate strength index of the hull cross-sections under a pure vertical bending moment for individual impact damaged scenarios.

\section{DEVELOPMENT OF DIAGRAMS}

6.1 Formulation of PDF 


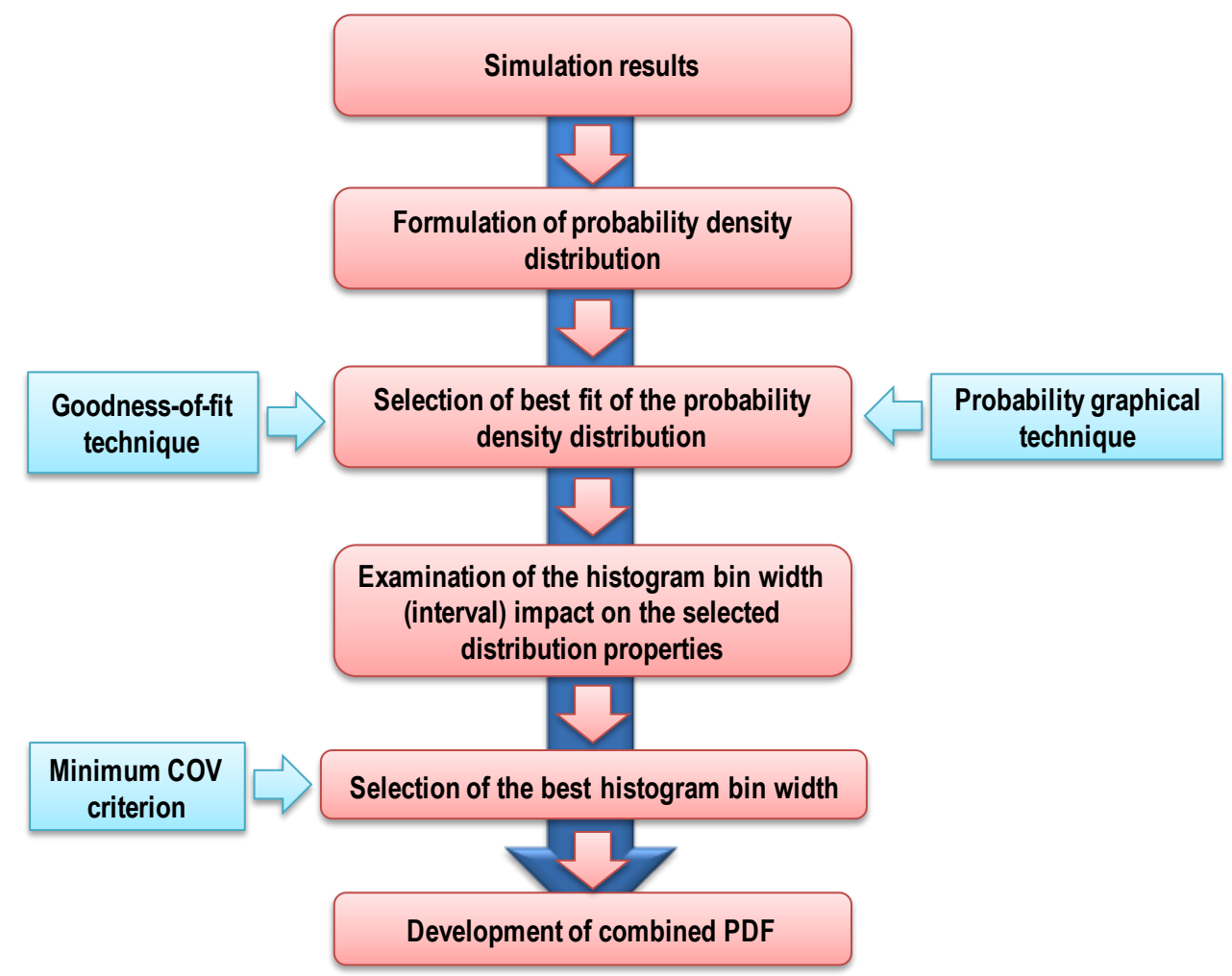

Fig. 14: The procedure used to develop the PDF.

The analysis of the post-simulation result recognized a statistical strategy to classify the damage sensitivity corresponding to the RSI for different ship lengths. Based on the observations, it is suggested that the respective ship lengths tend to follow specific distribution functions for the corresponding RSI. For the present study, 2-Parameter Weibull function is selected. The developed PDFs could assist in predicting the probability density function of the RSI of the target ship with respect to its length. The procedure presented in Figure 14 has an extended application of the statistical framework in analysing and formulating the simulation results.

Fifty simulation scenarios are considered for each type of tanker, to analyse the damaged ship's response in terms of the RSI for hogging and sagging, as discussed in Section 4. By using the GOF test, the best-fit distribution function for each condition of the simulation results is selected from $D_{n}$, as shown in Table 3. Although the logistic function comprises the minimum $D_{n}$ value for Aframax in hogging and for Suezmax in the sagging condition, a 2parameter Weibull distribution function has been selected to represent the simulation results of the individual PDFs for different ship lengths. This is to achieve a better estimation and comparative analysis for the purpose of this study. 
Table 3: The GOF test (K-S) statistics for the simulation results' PDFs

\begin{tabular}{|c|c|c|c|c|c|c|c|c|}
\hline \multirow{2}{*}{ Distribution function } & \multicolumn{7}{|c|}{ PDF test statistics for the RSI results } \\
\cline { 2 - 9 } & \multicolumn{2}{|c|}{ Panamax } & \multicolumn{2}{|c|}{ Aframax } & \multicolumn{2}{c|}{ Suezmax } & \multicolumn{2}{c|}{ VLCC } \\
\cline { 2 - 9 } & Hogging & Sagging & Hogging & Sagging & Hogging & Sagging & Hogging & Sagging \\
\hline 2-Parameter Weibull & 0.12030 & 0.12617 & 0.14330 & 0.08729 & 0.14828 & 0.11360 & 0.09891 & 0.16823 \\
\hline Exponential & 0.60806 & 0.60886 & 0.59777 & 0.60035 & 0.59814 & 0.59284 & 0.60399 & 0.58608 \\
\hline Normal & 0.13231 & 0.14484 & 0.14515 & 0.12175 & 0.19512 & 0.12852 & 0.13724 & 0.21640 \\
\hline Lognormal & 0.13335 & 0.14906 & 0.14767 & 0.12669 & 0.20121 & 0.13455 & 0.14112 & 0.22312 \\
\hline 2-Parameter Gamma & 0.13268 & 0.14773 & 0.14537 & 0.12480 & 0.19956 & 0.13139 & 0.14031 & 0.22198 \\
\hline Logistic & 0.15036 & 0.15828 & 0.13929 & 0.11248 & 0.20746 & 0.10790 & 0.15579 & 0.22650 \\
\hline Log-Logistics & 0.14799 & 0.15353 & 0.16472 & 0.13793 & 0.20623 & 0.14912 & 0.14273 & 0.22937 \\
\hline
\end{tabular}

\subsection{Mean and COV}

The effect of the histogram bin width on the statistical modelling is described in the previous section and the bin width which gives the maximum mean value and minimum COV should be selected (Paik et al. 2003). Figure 15 illustrates the diagrams of the calculated mean and COV at different RSI to indicate the best bin width value for different ship types under hogging and sagging conditions. The bin width selected using the calculated mean and COV diagram is applied to develop the PDF diagrams as shown in Figure 16.

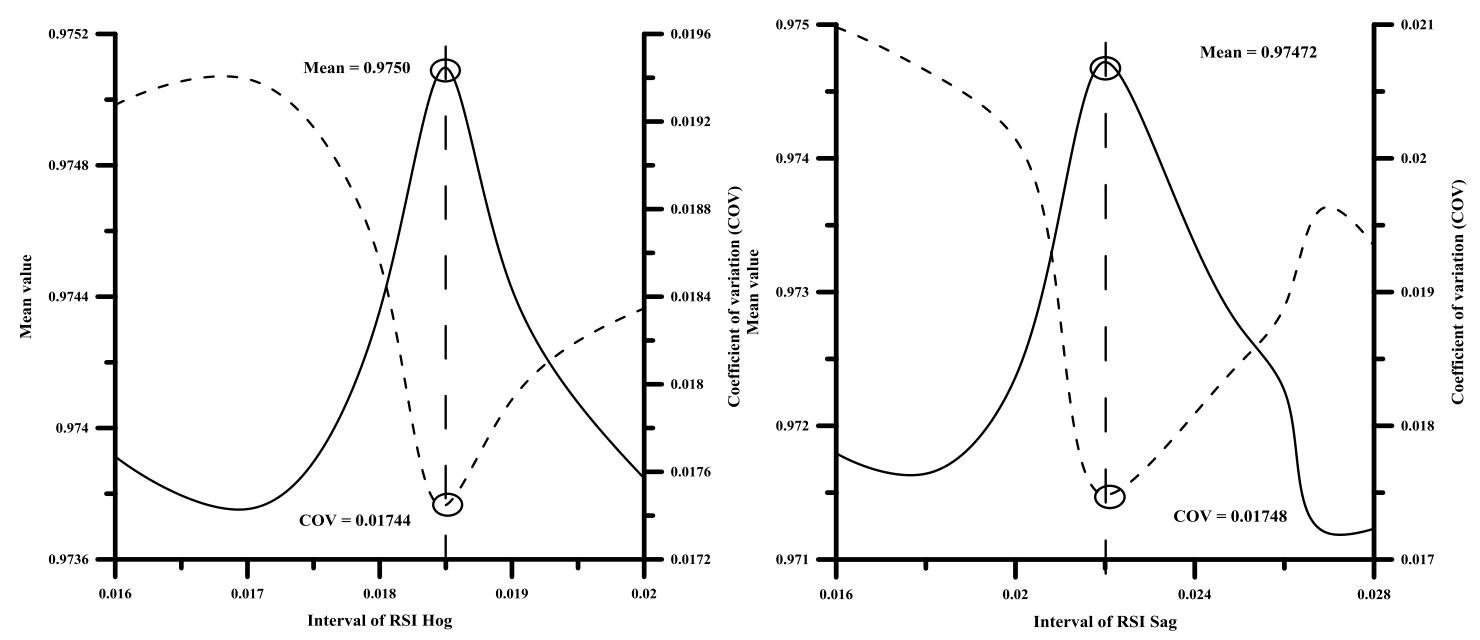

(a) Panamax 

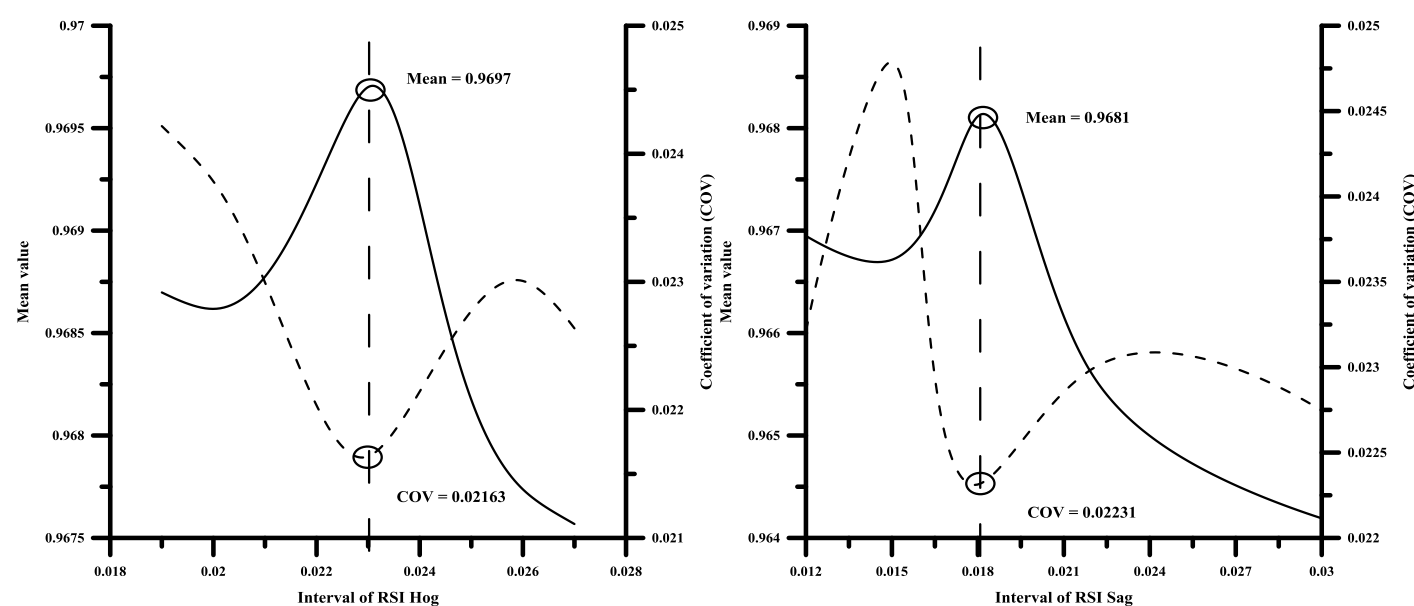

(b) Aframax
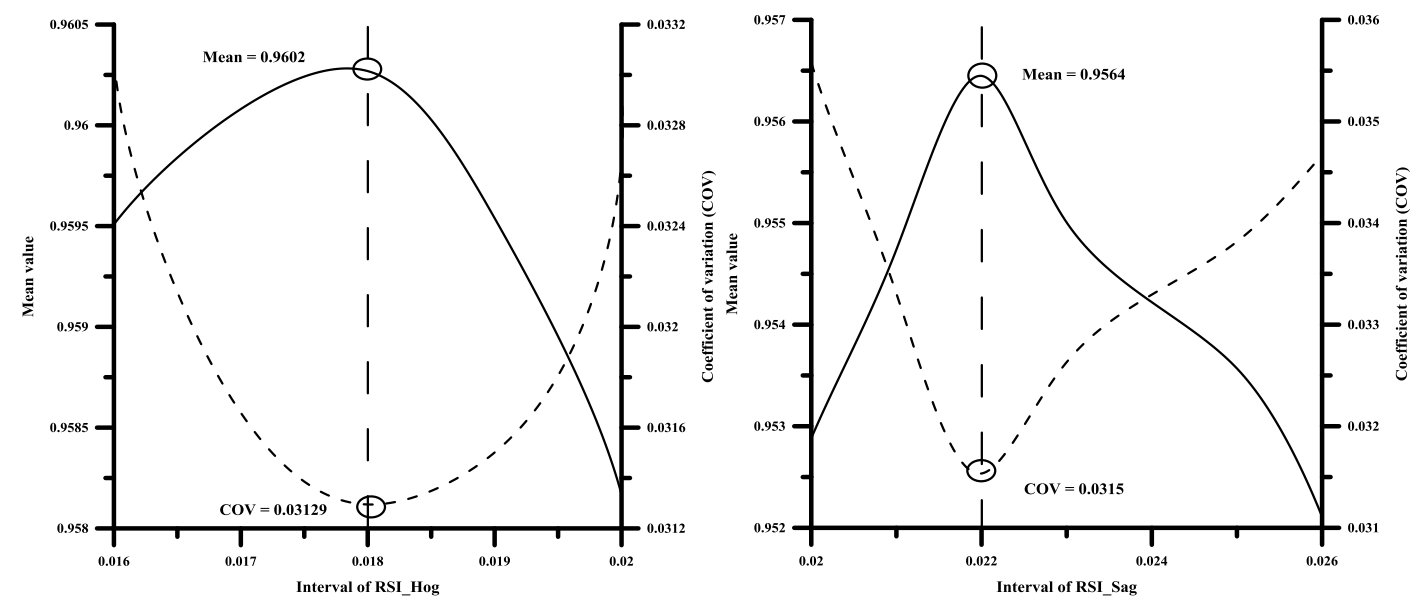

(c) Suezmax
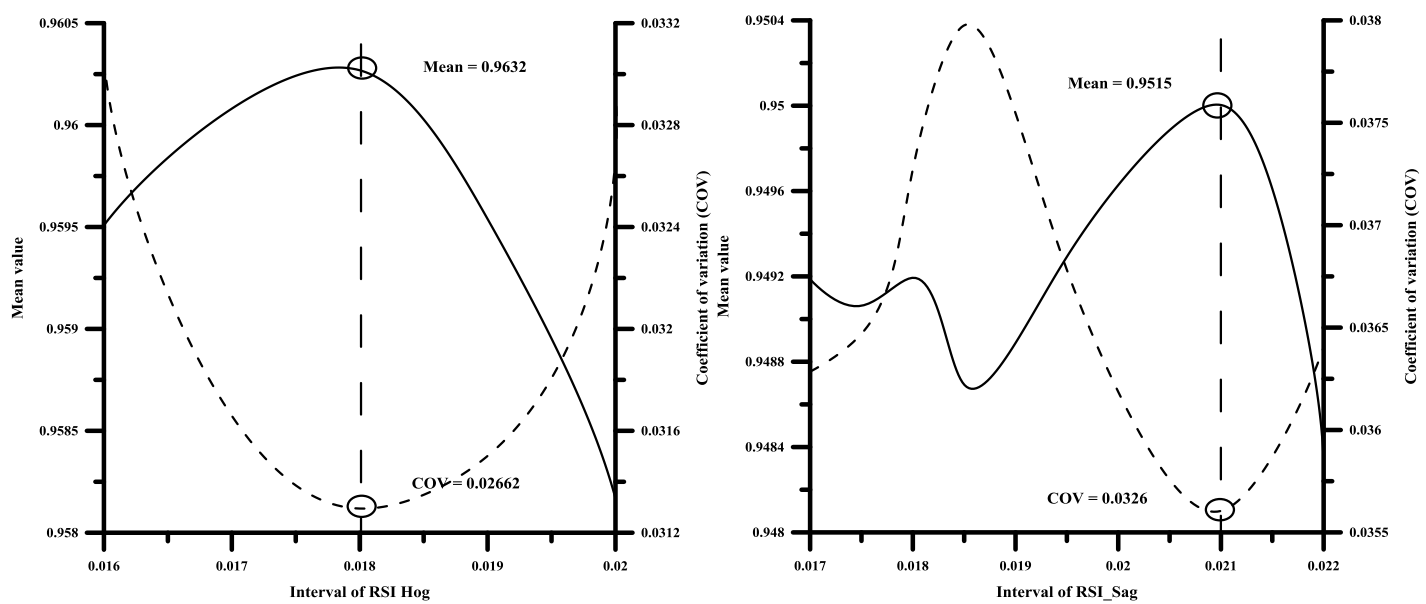

(d) VLCC

Fig. 15: Mean and COV diagrams 


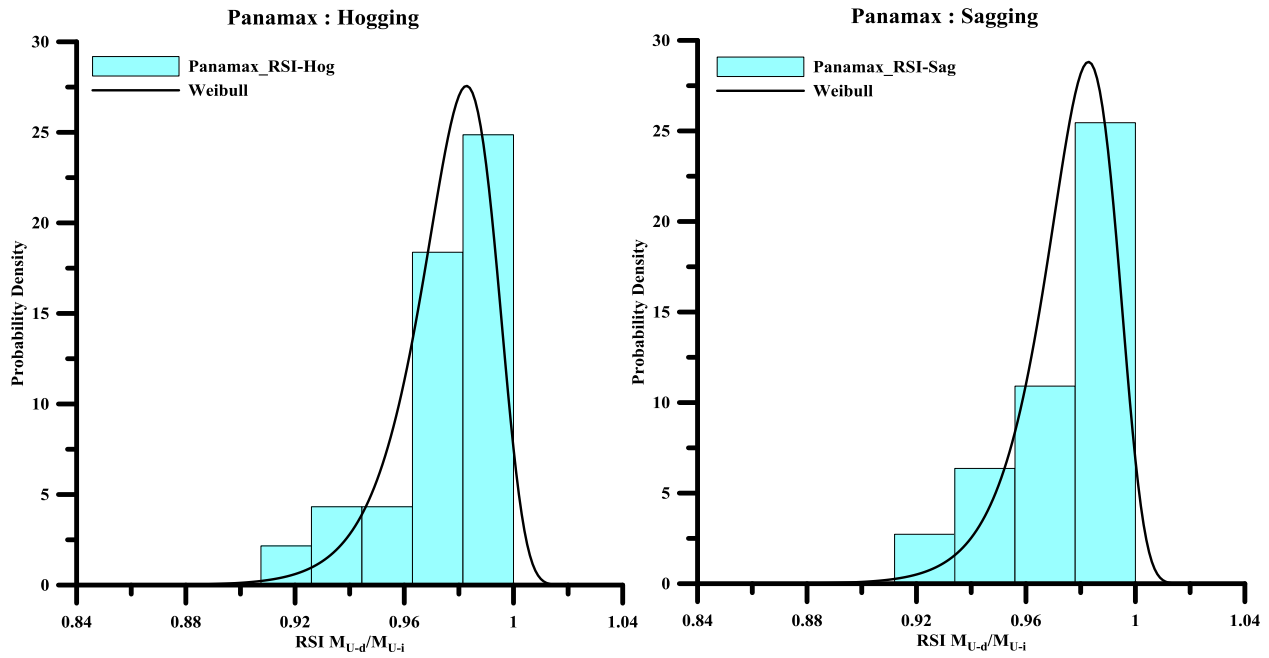

(a) Panamax
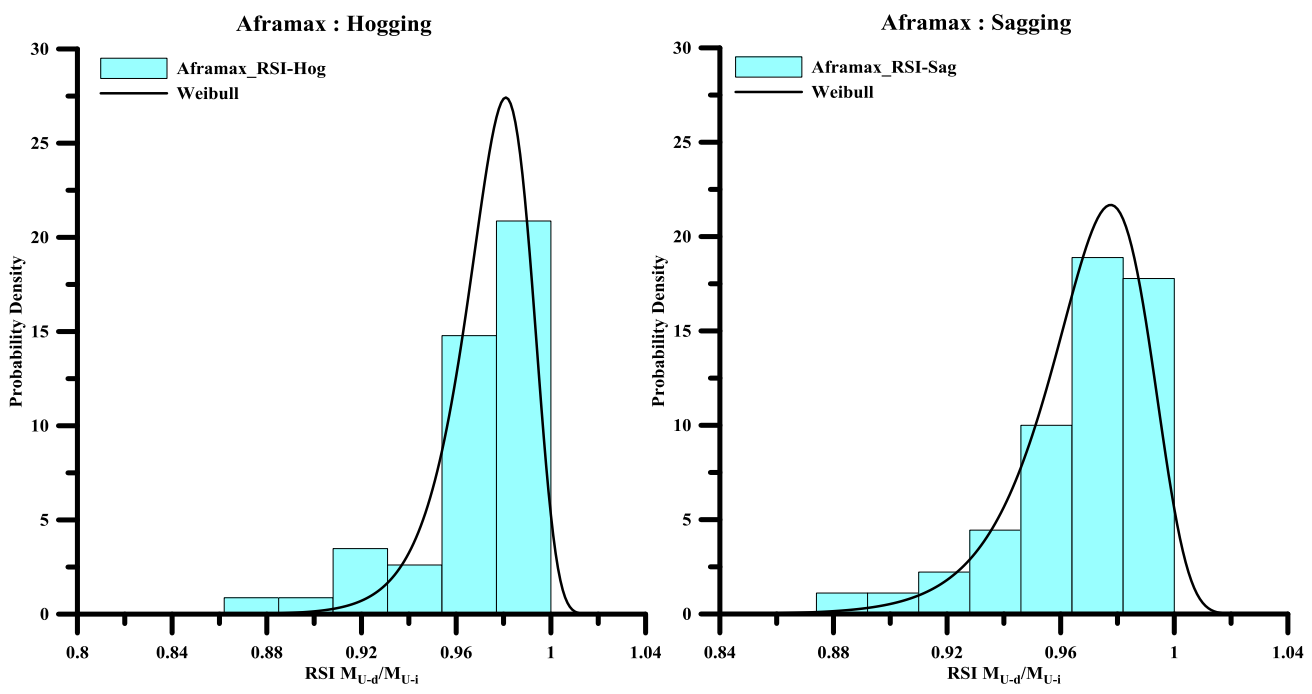

(b) Aframax

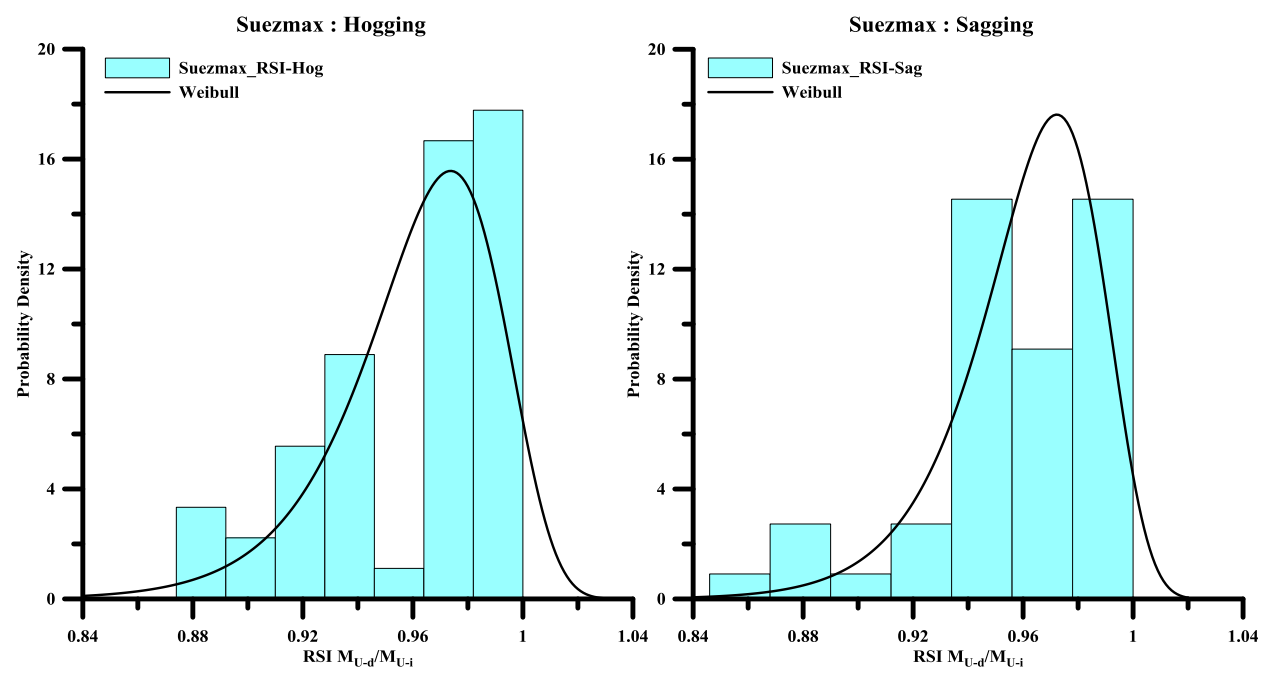

(c) Suezmax 

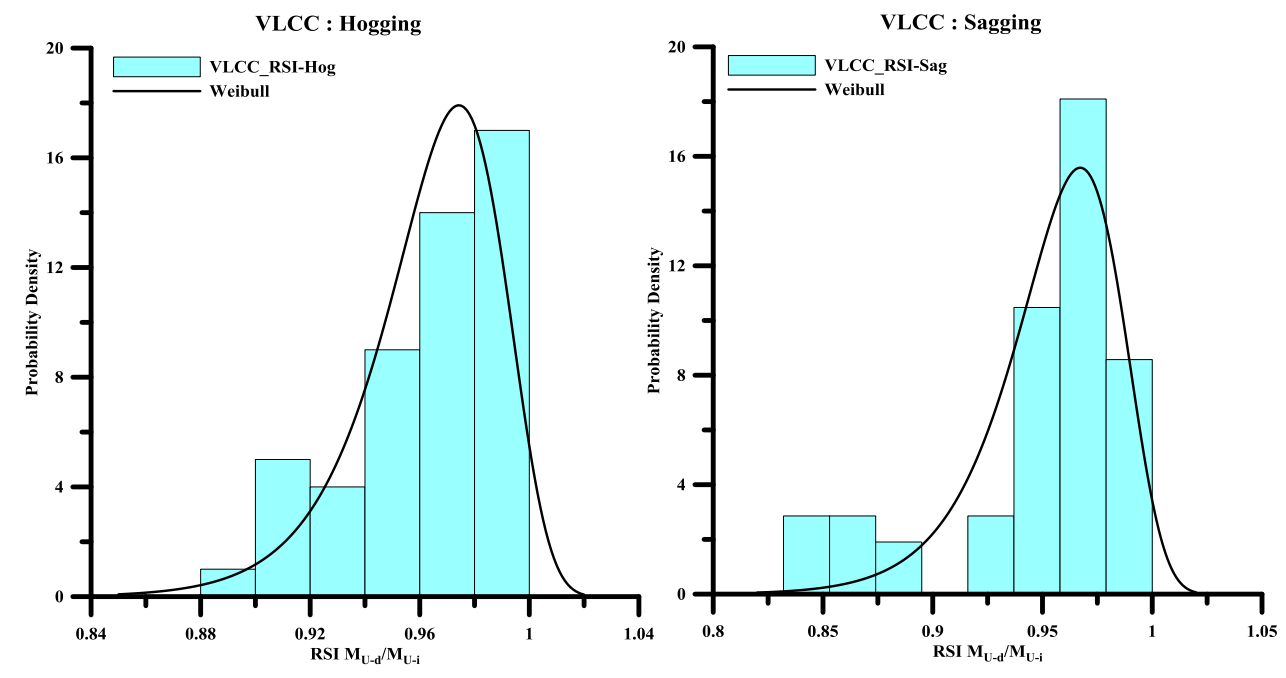

(d) VLCC

Fig. 16: Developed PDF diagrams.

\subsection{RSI versus ship length diagrams}

All developed diagrams for all tankers are then combined in two separate graphs, one for hogging and one for sagging. These diagrams are the RSI versus ship length. It is learned that for a commercial ship such as a tanker, the strength of the mid-ship cross-section is correspondent to the ship length. This means that the longer the tanker, the strength of the mid-ship cross-section is believed to be higher. Therefore, the ship length significantly influences the bending moment and is plotted against the RSI for further comparative analysis and formulation. The developed RSI versus ship length for hogging and sagging are shown in Figure 17.

PDF

PDF

PDF

PDF

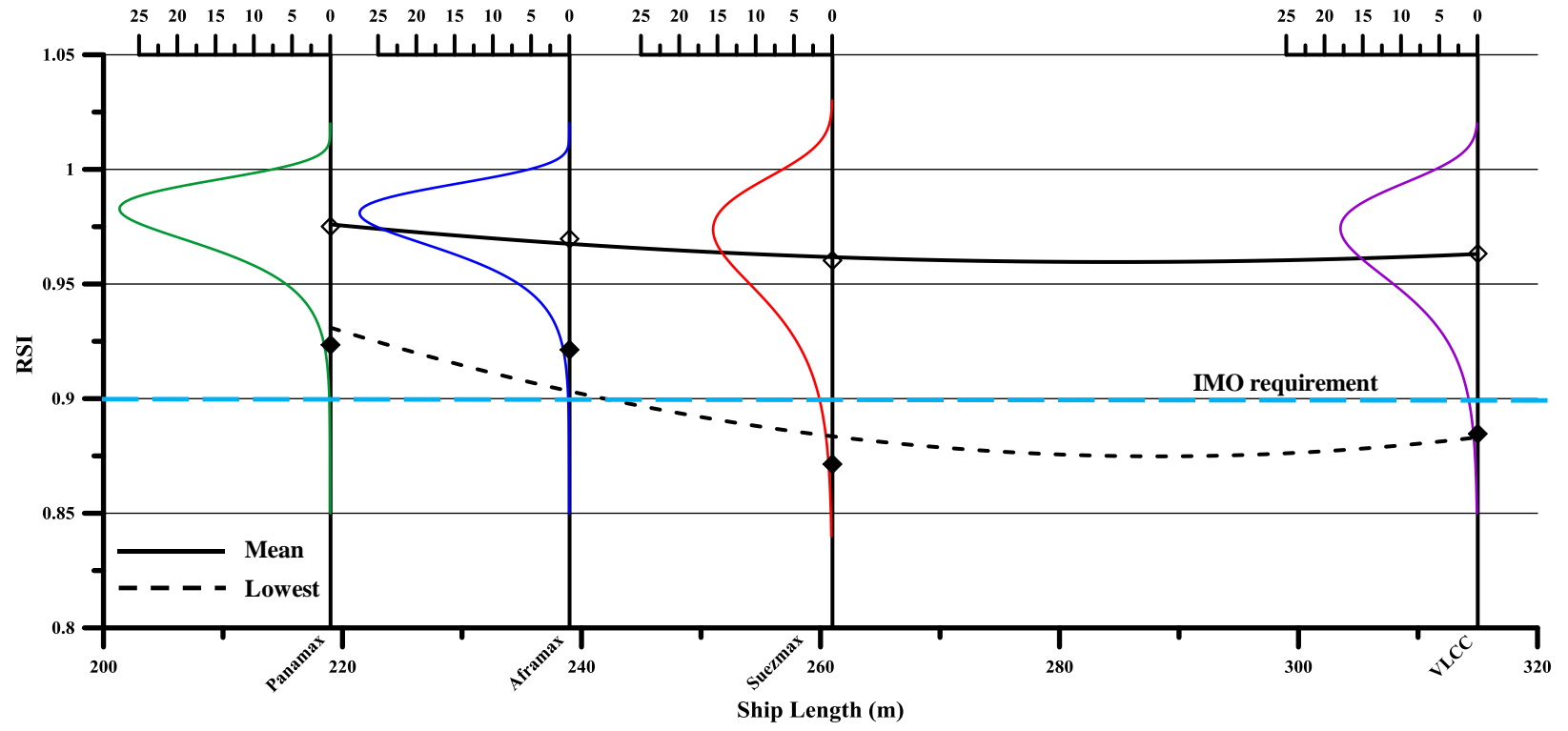


(a) Hogging condition

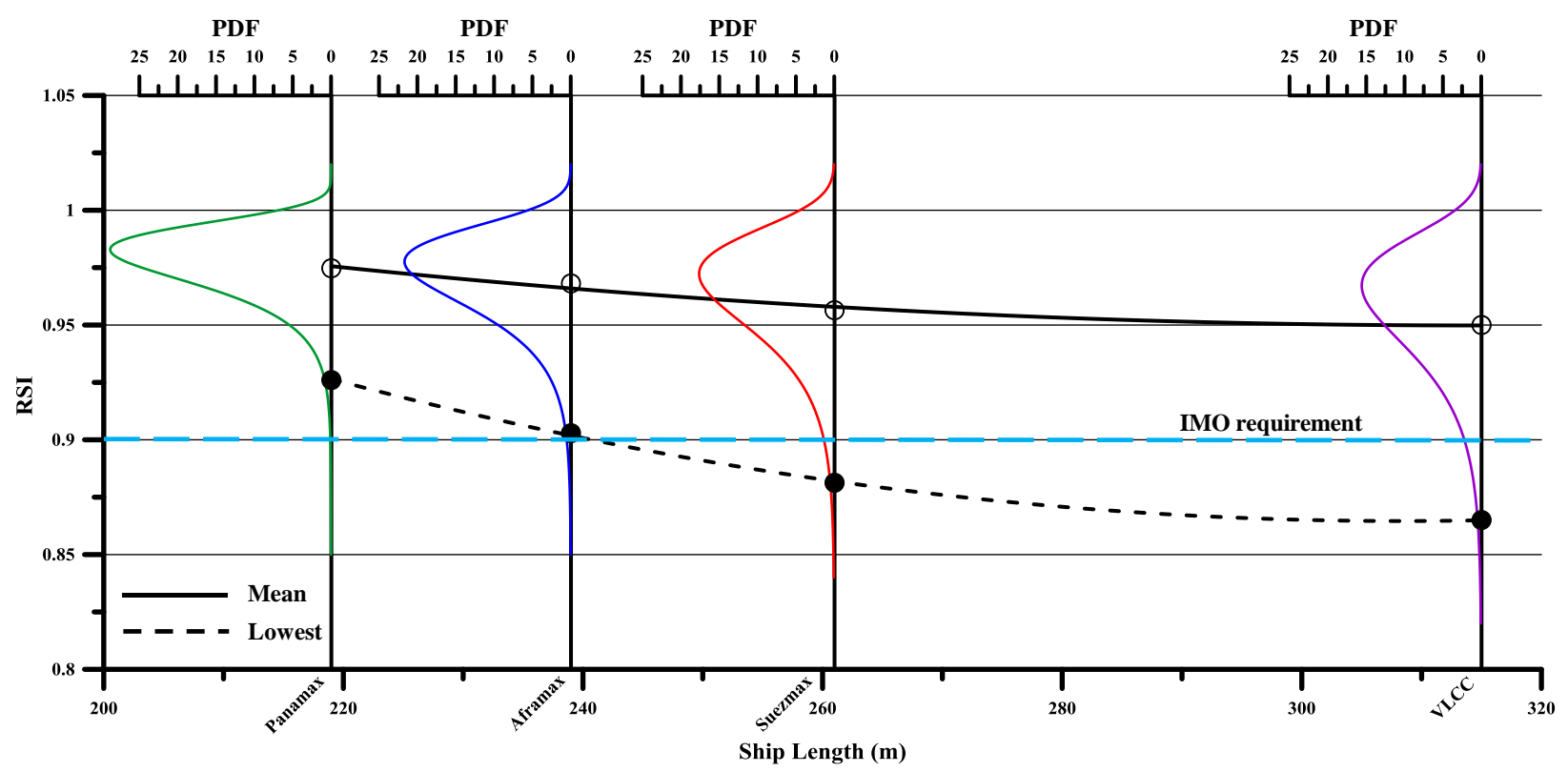

(b) Sagging condition

Fig. 17: RSI versus ship length.

The developed RSI versus ship length diagrams can provide an estimate of the damaged ship's Weibull function density distribution for different ship length only for double hull oil tankers. In the diagrams, the mean from each PDF is plotted and fitted to view the trends. The plotted mean in the diagrams can be used as a validation after creating the estimation Weibull PDF of other double hull oil tankers.

In addition, the lowest point of each PDF is also plotted. The lowest point for each PDF is an assumption of the lowest value in the PDF that still contributes value to the estimation and is taken from the $1 \%$ value of its cumulative density function. In comparison to the International Maritime Organisation's requirement (IMO 2002) for safety criteria of remaining strength after collision, the lowest line fitting is not uniform and can be used as a substitute for the $90 \%$ remaining capacity of the IMO requirement. This is based on the fact that the lowest fitting follows the exact strength capacity of each ship type compared to the IMO uniform requirement.

As mentioned previously, the 2-parameter Weibull function represents the RSI for the post-collision impact damage to double hull oil tankers and the function can then be rewritten as follows:

$$
f_{c}=\frac{\alpha}{\beta}\left(\frac{Y_{e}}{\beta}\right)^{\alpha-1} \cdot \exp \left[-\left(\frac{Y_{e}}{\beta}\right)^{\alpha}\right]
$$

where, $f_{c}$ is a function of the RSI density and $Y_{e}$ itself is the RSI. The two parameters (alpha) and (beta) are the important governing parameters for Weibull function, representing shape and scale respectively.

The combined PDF graphs provide an estimation of the Weibull density distribution of the RSIs for different ship lengths. A new estimation PDF for another ship, with a different length, can be developed by using the same 2- 
parameter Weibull function. The two parameters, alpha and beta, can be approximated by the following continuous formulas (Equations 6.1 and 6.2), while Figure 18 illustrates the diagrams of alpha and beta versus ship length.

(a) Hogging condition

$$
\begin{aligned}
& \text { Shape }=6.80 \times 10^{-3} \cdot(L)^{2}-3.97 \cdot L+621.28 \\
& \text { Scale }=1.80 \times 10^{-6} \cdot(L)^{2}-1.06 \times 10^{-3} \cdot L+1.13
\end{aligned}
$$

where $L$ is the ship's length in $\mathrm{m}$.

(b) Sagging condition

$$
\begin{aligned}
& \text { Shape }=6.72 \times 10^{-3} \cdot(L)^{2}-3.96 \cdot L+620.98 \\
& \text { Scale }=1.53 \times 10^{-6} \cdot(L)^{2}-9.80 \times 10^{-4} \cdot L+1.12
\end{aligned}
$$

where $L$ is the ship's length in $\mathrm{m}$.

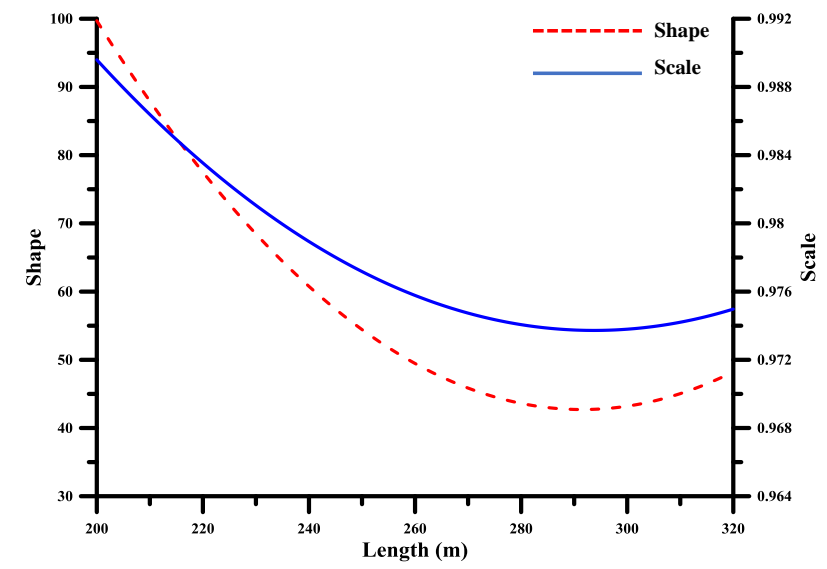

(a) Hogging condition

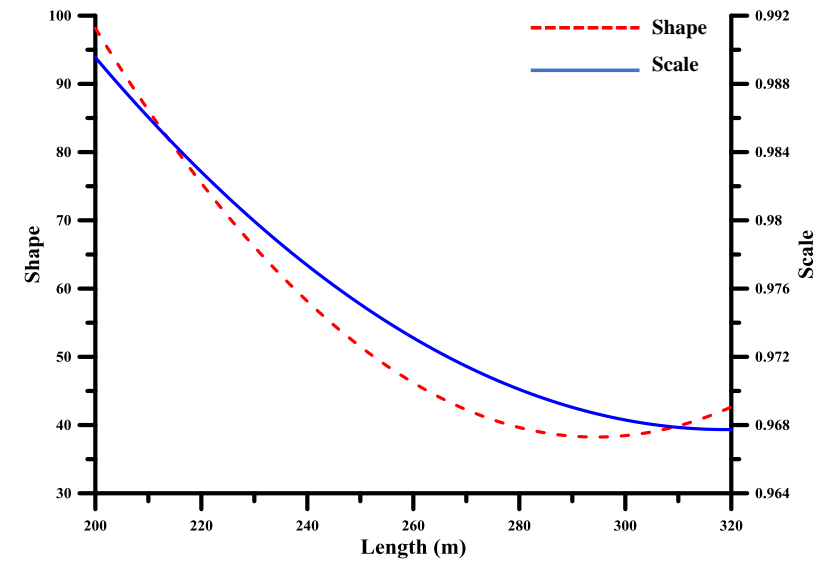

(b) Sagging condition

Fig. 18: The 2-parameter Weibull function's shape and scale diagrams versus ship length for hogging and sagging conditions.

\section{CONCLUSION}

The statistical and probabilistic method to derive the residual strength index (RSI) of ships particularly to shipship collision was studied to develop a rapid method for hull collapse strength calculations of double hull oil tankers after collisions. Thus, the simplified analytical method was developed based on the observations of the numerical simulation. The focus was on identifying the statistical characteristics of the damaged double hull oil tankers involved in collisions in terms of the residual strength index and ship length. It is notably noted that the findings may govern new guidelines. 
In the study, the probabilistic approach was applied in creating the damaged ship scenario simulations to take account the full range of possible cases. To predict structural crash worthiness, the entire process of post-collision impact damaged ship scenario selection and the application of the proposed analytical method was presented. As per the simulation results associated with the residual strength index, the developed probability density functions were compiled in one graph (refer to Fig. 17). The developed probability density functions eventually can be utilized to estimate sets of the residual strength indices for the damaged double hull oil tankers in less complicated simulation process and in a shorter time frame.

The lowest fitting illustrated in the diagrams can substitute the $90 \%$ remaining capacity from the IMO safety collision requirement provided that the lowest follows the exact strength of each ship type in compliance to the IMO uniform requirement. For future reference, it is recommended that the damaged double hull oil tankers obtained from the probability density functions may assist engineers or clients in drawing the concept design to predict the collision impact damage probability density. This can be practically carried out by proposing the range of collision strengths and defining the upper and lower limits in concept design. Hence, the mean or the lowest fitting obtained can be proposed as the upper limit of the designed ship's strength conducted.

\section{Acknowledgements}

This study was undertaken at the Lloyd's Register Foundation Research Centre of Excellence at Pusan National University. Lloyd's Register Foundation invests in science, engineering and technology for public benefit, worldwide.

\section{References}

ABS. 1995. Guide for assessing hull girder residual strength. American Bureau of Shipping, Houston, TX, USA.

ALPS/HULL. 2016. Progressive collapse analysis of ship's hull structures. Marine Technology Center, DRS Technologies, Stevensville, MD, USA.

C4TX. 2015. CTX Casualty Database [Internet]. [cited 2 June 2015]. Available from: http://c4tx.org/ctx/job/cdb/ summary.html

Chakravarty IM, Roy JD, Laha RG. 1967. Handbook of Methods of Applied Statistics.

Chen KY. 1983. Ultimate strength of ship structures. Trans SNAME. 91:149-168.

DNV. 2004. Rules for ships. A 300 collision and grounding. Det Norske Veritas, Oslo, Norway. Pt. 5 Ch. 15 Sec. 3.

Garrè L, Rizzuto E. 2012. Bayesian networks for probabilistic modelling of still water bending moment for sidedamaged tankers. Ships Offshore Struct. 7:269-283. 
Haris S, Amdahl J. 2012. Crushing resistance of a cruciform and its application to ship collision and grounding. Ships Offshore Struct. 7:185-195.

Hong L, Amdahl J. 2008. Plastic mechanism analysis of the resistance of ship longitudinal girders in grounding and collision. Ships Offshore Struct. 3:159-171.

Horn SA, Neal CP. 1981. The Atlantic Empress sinking - a large spill without environmental disaster. In: Int Oil Spill Conf. Vol. 1981. New York, USA: American Petroleum Institute; 429-435.

Hughes OF, Paik JK. 2013. Ship structural analysis and design. Alexander, USA: Society of Naval Architects and Marine Engineers.

ISSC. 2009. Damage assessment after accidental events. International Ship and Offshore Structures Congress. Seoul, Korea

IACS. 2014. Common structural rules for bulk carriers and oil tankers. Hull girder residual strength. International Association of Classification Societies. London, UK. Pt. 1 Ch. 5 Sec. 3.

IMO. (2002). SOLAS/2 recommended longitudinal strength. Maritime Safety Committee. International Maritime Organisation. London, UK. MSC.108(73).

Khan IA, Das PK. 2008. Reliability analysis of intact and damaged ships considering combined vertical and horizontal bending moments. Ships Offshore Struct. 3:371-384.

Kim DK, Kim BJ, Seo JK, Kim HB, Zhang X, Paik JK. 2014. Time-dependent residual ultimate longitudinal strength-grounding damage index (RD) diagram. Ocean Eng. 76:163-171.

Kim DK, Pedersen PT, Paik JK, Kim HB, Zhang X, Kim MS. 2013. Safety guidelines of ultimate hull girder strength for grounded container ships. Saf Sci [Internet]. 59:46-54.

Kim YS, Youssef S, Ince S, Kim SJ, Seo JK, Kim BJ, Ha YC, Paik JK. 2015. Environmental consequences associated with collisions involving double hull oil tanker. Ships Offshore Struct. 1-9. Available from: http://www.tandfonline.com/doi/full/10.1080/17445302.2015.1026762

Lee TK, Kim JD, Shin BC, Chun TB. 2001. Experimental study on the collision strength of VLCC side structures. Int J Offshore Polar Eng. 11:113-117.

Lopes R, Reid I, Hobbes P. 2007. The Two-Dimensional Kolmogorov-Smirnov Test XI International Workshop on Advanced Computing and Analysis Techniques in Physics Research, Amsterdam. Publ by Proc Sci.

Lützen M. 2001. Ship Collision Damage. PhD Thesis. Technical University of Denmark, Lyngby, Denmark. 
Magoga T, Flockhart C. 2014. Effect of weld-induced imperfections on the ultimate strength of an aluminium patrol boat determined by the ISFEM rapid assessment method. Ships Offshore Struct. 9:218-235.

Obisesan A, Sriramula S, Harrigan J. 2015. A framework for reliability assessment of ship hull damage under ship bow impact. Ships Offshore Struct [Internet]. 1-20. Available from:

http://www.tandfonline.com/doi/full/10.1080/17445302.2015.1051281

Paik JK. 2007. Practical techniques for finite element modelling to simulate structural crashworthiness in ship collisions and grounding (Part II: Verification). Ships Offshore Struct. 2:81-85.

Paik JK, Chung JY, Choe IH, Thayamballi AK, Pedersen PT. 2005. On the rational design of double hull tanker structures against collision. HHI Eng Rev. 25:41-51.

Paik JK, Kim DK, Park DH, Kim HB, Kim MS. 2012. A new method for assessing the safety of ships damaged by grounding. Int J Marit Eng. 154:A1-A20.

Paik JK, Kim DK, Park DH, Kim HB, Mansour AE, Caldwell JB. 2013. Modified Paik-Mansour formula for ultimate strength calculations of ship hulls. Ships Offshore Struct. 8:245-260.

Paik JK, Lee JM, Hwang JS, Park YII. 2003. A time-dependent corrosion wastage model for the structures of singleand double-hull tankers and FSOs and FPSOs. Mar Technol. 40:201-217.

Paik JK, Pedersen PT. 1996. Modelling of the internal mechanics in ship collisions. Ocean Eng. 23:107-142.

Paik JK, Thayamballi AK, Yang SH. 1998. Residual Strength Assessment of Ships after Collision and Grounding. Marine tech. 35:38-54.

Paik JK, Thayamballi AK. 2003. Ultimate limit state design of steel-plated structures. England: John Wiley \& Sons.

Pill I, Tabri K. 2011. Finite element simulations of ship collisions: a coupled approach to external dynamics and inner mechanics. Ships Offshore Struct. 6:59-66.

Rawson C, Crake K, Brown A. 1998. Assessing the environmental performance of tankers in accidental grounding and collision. Presented at the SNAME Annual Meeting, San Diego, California.

Ringsberg JW. 2010. Characteristics of material, ship side structure response and ship survivability in ship collisions. Ships Offshore Struct. 5:51-66.

Santos TA, Soares, CG. 2008. Global loads due to progressive flooding in passenger ro-ro ships and tankers. Ships Offshore Struct. 3:289-303.

Smith C. 1977. Influence of local compressive collapse on ultimate longitudinal strength of a ship's hull. In: Proc Int Symp PRADS, Tokyo, Japan. 
Tabri K. 2012. Influence of coupling in the prediction of ship collision damage. Ships Offshore Struct. 7:47-54.

Tavakoli MT, Amdahl J, Leira BJ. 2012. Analytical and numerical modelling of oil spill from a side tank with collision damage. Ships Offshore Struct. 7:73-86.

Taylor P, Kim YS, Youssef S, Ince S, Kim SJ, Seo JK, Ju B, Ha YC, Paik JK. 2015. Environmental consequences associated with collisions involving double hull oil tanker. Ships Offshore Struct. 37-41.

Tournadre J. 2014. Anthropogenic pressure on the open ocean: the growth of ship traffic revealed by altimeter data analysis. Geophys Res Lett. 41:7924-7932.

Ueda Y, Rashed SM, Paik JK. 1986. Plate and stiffened plate units of the idealised structural unit method (2nd Report): under in-plane and lateral loading considering initial deflection and residual stress. J Soc Nav Archit Japan. 160.

Ueda Y, Rashed SMH, Paik JK. 1984. Plate and stiffened plate units of the idealised structural unit method (1st Report). J Soc Nav Arch Japan. 156:366-377.

Villavicencio R, Liu Z, Amdahl J, Soares CG. 2013a. Influence of the neutral axis displacement on the residual strength of a damaged tanker double-bottom structure. Ships Offshore Struct. 8:663-674.

Villavicencio R, Kim Y-H, Cho S-R, Soares CG. 2013b. Deformation process of web girders in small-scale tanker double hull structures subjected to lateral impact. Mar Struct. 32:84-112.

Wang G, Spencer J, Chen Y. 2002. Assessment of a ship's performance in accidents. Mar Struct. 15:313-333.

Wang, G., Arita, K., Liu, D., 2000. Behavior of a double hull in a variety of stranding or collision scenarios. Mar.

Struct. 13, 147-187. Available from: http://dx.doi.org/10.1016/S0951-8339(00)00036-8

Youssef SAM, Faisal M, Seo JK, Kim BJ, Ha YC, Kim DK, Paik JK, Cheng F, Kim MS. 2015. Assessing the risk of ship hull collapse due to collision. Ships Offshore Struct. 1-16. Available from:

http://www.tandfonline.com/doi/abs/10.1080/17445302.2014.993110

Youssef SAM, Ince ST, Kim YS, Paik JK, Cheng F, Kim MS. 2014. Quantitative risk assessment for collisions involving double hull oil tankers. Int J Marit Eng. 156:157-174.

Zhang A, Suzuki K. 2006. Numerical simulation of fluid-structure interaction of liquid cargo filled tank during ship collision using the ALE finite element method. Int J Crashworthiness. 11:291-298.

Zhang S. 1999. The Mechanics of Ship Collisions. PhD Thesis. Technical university of Denmark, Denmark. 
Zhang X, Paik JK, Jones, N., 2015. A new method for assessing the shakedown limit state associated with the breakage of a ship's hull girder. Ships Offshore Struct. 1-13. Available from:

http://www.tandfonline.com/doi/abs/10.1080/17445302.2014.993109.

Zheng Y, Aksu S, Vassalos D, Tuzcu C. 2007. Study on side structure resistance to ship-ship collisions. Ships Offshore Struct. 2:273-293. 